
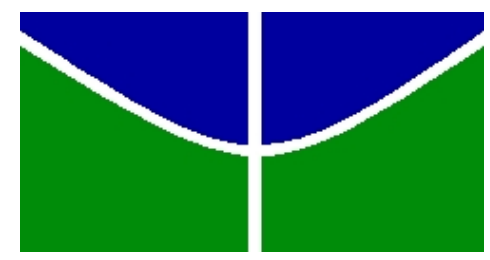

Universidade de Brasília

Departamento de Processos Psicológicos Básicos

Programa de Pós-graduação em Ciências do Comportamento

RODRIGO MARQUEZ MARTINS DE OLIVEIRA

METACONTINGÊNCIA: UM EXPERIMENTO COM VARIABILIDADE

OPERANTE DO PRODUTO AGREGADO

Brasília 
RODRIGO MARQUEZ MARTINS DE OLIVEIRA

Metacontingência: um experimento com variabilidade operante do produto agregado

Dissertação apresentada ao Programa de PósGraduação em Ciências do Comportamento, Departamento de Processos Psicológicos Básicos, Instituto de Psicologia, Universidade de Brasília, como parte dos requisitos para obtenção do grau de Mestre em Ciências do Comportamento.

Orientador: Dr. João Claudio Todorov 


\section{Metacontingência: um experimento com variabilidade operante do produto agregado}

Dissertação apresentada ao Programa de PósGraduação em Ciências do Comportamento, Departamento de Processos Psicológicos Básicos, Instituto de Psicologia, Universidade de Brasília, como parte dos requisitos para obtenção do grau de Mestre em Ciências do Comportamento.

Este trabalho foi desenvolvido no Instituto de Psicologia da Universidade de Brasília com apoio da CAPES.

Aprovado em:

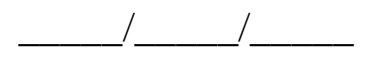

Banca Examinadora:

Prof. Dr. João Claudio Todorov (Presidente)

Universidade de Brasília

Prof. Dr. Carlos Renato Xavier Cançado (Membro Efetivo)

Universidade de Brasília

Prof $^{a}$. Dr ${ }^{\mathrm{a}}$. Luciana Verneque (Membro Efetivo)

Instituto Brasiliense de Análise do Comportamento - IBAC

Prof $^{\mathrm{a}} . \mathrm{Dr}^{\mathrm{a}}$. Eileen Pfeiffer Flores (Membro Suplente)

Universidade de Brasília 


\section{AGRADECIMENTOS}

Durante minha graduação, aprendi com meus primeiros professores de Análise do Comportamento que ciência é cooperação, e a cada passo que dou em minha trajetória acadêmica isso fica mais claro. Aprender não é sempre um processo fácil, mas uma série de pessoas tornou meu aprendizado mais suave e divertido nestes dois últimos anos e merecem o meu agradecimento eterno.

Agradeço primeiramente aos meus pais pelo suporte, em especial à minha mãe, que tem me feito ir cada vez mais longe graças ao seu apoio financeiro e emocional. Não é fácil encarar mudanças de cidades e rotinas, mas saber que tenho um porto seguro sempre me trouxe paz nos momentos de incerteza.

À minha família, que nunca me deixou desamparado, em especial aos meus padrinhos maravilhosos, que foram providencialmente escolhidos. À tia Norma, que mais uma vez me ajudou a mobiliar uma casa. À minha vó Marley, que me acolheu, cuidou de mim quando fiquei doente e me encheu de guloseimas.

Aos professores André Bravin, Fábio e Marcelo por terem me apresentado a Análise do Comportamento de forma tão cativante e ido além de suas atribuições profissionais para investirem em minha formação. Tão importante quanto o papel de vocês em grandes escolhas que fiz, é a amizade que temos hoje.

Aos meus amigos de Jataí, em especial os do LPPB, pelas horas em que divagávamos sobre a vida e o futuro. Apesar da distância, vocês sempre estavam presentes em minha caminhada, Aline, Isabela, Lyris, Lívia, Max, Naiara, Nathália e Vinícius.

À Bianca e a Isabela por terem dividido estes dois anos de Brasília comigo. Tudo foi mais fácil por conta de vocês e já sinto falta dos nossos jantares, dos filmes, da correria, de ficarmos batendo papo no sofá da sala, dos espetinhos, sushis... 
Aos meus companheiros de jornada - e novos amigos -, Rafa, Fabi, Roberta, Marcelo, Jon, Iza, Adriana e Gleiton, que sempre se prontificaram a me ajudar e tornaram meus dias mais divertidos, pessoalmente ou por hangout. Foi muito bom estar com vocês.

Ao João Vianney, não só por ter desenvolvido o programa que utilizei neste trabalho, mas por ser um profissional extremamente solícito e prestativo.

Aos funcionários do Instituto de Psicologia da UnB, pelo suporte e competência.

Aos professores do PPB, que, apesar de muitas vezes estarem sob condições adversas, desempenham o seu trabalho com excelência.

Ao Gustavo Tozzi, Fabi e funcionários do IBAC pela acolhida e por terem viabilizado minha coleta de dados. Vocês foram espetaculares.

Ao Professor Todorov por ter compartilhado parte de seu conhecimento e sua história comigo, por se dedicar de forma tão generosa à ciência e a formação de seus orientandos e pelo acompanhamento durante minha jornada. Lembro de quando fui ao meu primeiro encontro da ABPMC em 2007 e fiquei maravilhado ao ver o autor que havia me introduzido na abordagem analítico-comportamental com seus artigos e traduções. Desde então minha admiração só cresce.

Por fim, agradeço a todos que estiveram ao meu lado - citados aqui, ou não - durante este desafio. Sem vocês tudo teria sido mais difícil. 


\section{RESUMO}

OLIVEIRA, R. M. M. de (2015). Metacontingência: um experimento com variabilidade operante do produto agregado. Dissertação de Mestrado, Instituto de Psicologia, Universidade de Brasília, Brasília.

A metacontingência consiste em uma ferramenta conceitual utilizado para estudo de práticas culturais pela Análise do Comportamento. É composta por contingências comportamentais entrelaçadas que produzem um produto agregado mantido por suas consequências. Da mesma forma ocorre em contingências individuais, é possível estabelecer infinitos esquemas de seleção cultural, porém a área ainda carece de uma uniformidade na utilização da terminologia e de avanços metodológicos que contribuam para o seu desenvolvimento empírico. A fim de trazer contribuições sobre a variabilidade de práticas culturais, o presente estudo teve como objetivo verificar o estabelecimento de uma metacontingência lag n. Buscou-se analisar se é possível produzir padrões variáveis nos produtos agregados de uma metacontingência mantida por consequências sociais. Para tanto, foram realizados três experimentos com um total de 16 participantes. A atividade consistiu em um jogo onde os participantes eram organizados em duplas e deveriam movimentar suas peças a fim de se encontrarem em um tabuleiro virtual. No Experimento I, havia quatro fases: "Linha de Base", "Lag 1", "Lag 2" e "Extinção". No Experimento II, havia cinco fases: "Linha de Base", "Lag 1", "Lag 2", "Extinção" e "Retorno à Linha de Base". E no Experimento III, havia seis fases: "Linha de Base", "Lag 1", "Lag 2", "Lag 3", "Extinção" e "Retorno à Linha de Base". Na metacontingência lag n, era necessário que o produto agregado produzido pela dupla fosse diferente do produto produzido em $n$ tentativas anteriores para que a consequência programada fosse apresentada. As medidas analisadas foram: a quantidade de partidas realizadas, a quantidade de movimentos e os valores do índice estatístico U em cada fase dos experimentos para verificar a variabilidade na localização do produto agregado. Os experimentos realizados mostraram que é possível aumentar a variabilidade de propriedades do produto agregado de uma metacontingência consequênciando diferentes padrões de variabilidade.

Palavras-chave: Metacontingência. Variabilidade cultural. Lag n. Humanos. Cultura. 


\begin{abstract}
OLIVEIRA, R. M. M. de (2015). Metacontingency: an experiment with operant variability of the aggregate product. Masters Thesis, Institute of Psychology, Universidade de Brasília, Brasília.

The metacontingency consists in a behavioral-analytic tool used to study cultural practices. It is composed of interlocked behavioral contingencies that produce an aggregate product maintained by its consequences. Similarly to what occurs in individual contingencies, you can establish various cultural selection schedules, but the area still lacks a uniform terminology and methodological advances that would contribute to its empirical development. In order to provide further contributions to the study of the variability of cultural practices, this study aimed to verify the establishment of a metacontingency lag $\mathrm{n}$. We sought to examine whether it is possible to produce varying patterns in the aggregate product of a metacontingency maintained by social consequences. Three experiments were conducted with a total of 16 participants. The activity consisted of a game which the participants played pairs and should move their icons to meet in a virtual board. In the Experiment I, there were four phases: "Baseline", "Lag 1", "Lag 2" and "Extinction". In Experiment II, there were five phases: "Baseline", "Lag 1", "Lag 2", "Extinction" and "Return to Baseline". In Experiment III, there were six phases: "Baseline", "Lag 1", "Lag 2", "Lag 3", "Extinction" and "Return to Baseline". In metacontingency lag n, it was necessary that the aggregate product produced by the pair of participants was different from the product produced in $n$ previous attempts for the consequence be presented. The measures analyzed were: the number of matches held the amount of movements and the U-value statistic for each phase of all experiments, to verify the variability in the location of the aggregate product. The experiments showed that it is possible to increase the variability of properties of aggregate product in a metacontingency by establishing consequences for different patterns of variability.
\end{abstract}

Keywords: Metacontingency. Cultural variability. Lag n. Humans. Culture. 


\section{LISTA DE FIGURAS}

Figura 1 - Tabuleiro do software "Xadrez” visível aos participantes...................................28

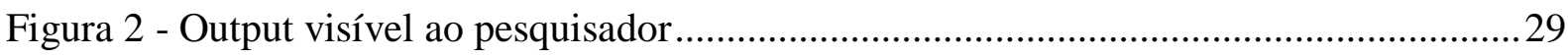

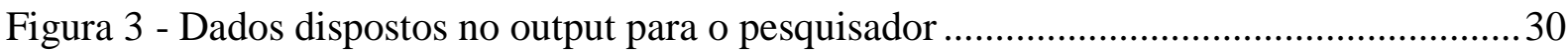

Figura 4 - Apresentação na tela do computador da consequência social programada .............32

Figura 5 - Média da quantidade de movimentos por fase dos experimentos ..........................39 


\section{LISTA DE QUADROS}

Quadro 1 - Descrição das fases dos experimentos 34

Quadro 2 - Quantidade de partidas por dupla em cada fase dos experimentos 37

Quadro 3 - Quantidade de partidas necessárias por dupla até para atingirem o critério de estabilidade de cada fase dos experimentos .38

Quadro 4 - Quantidade de movimentos por dupla em cada fase dos experimentos 39

Quadro 5 - Valores do índice estatístico U de cada dupla por fase dos experimentos 41 


\section{SUMÁRIO}

1 INTRODUÇÃ

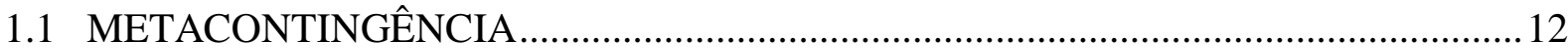

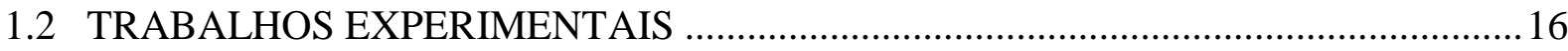

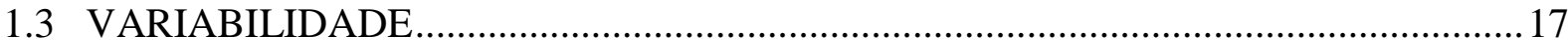

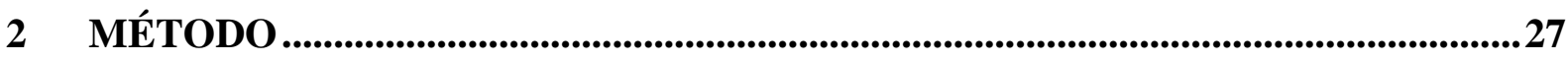

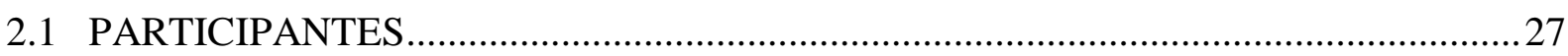

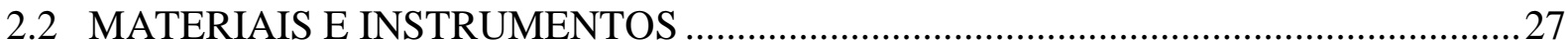

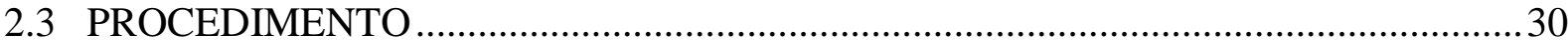

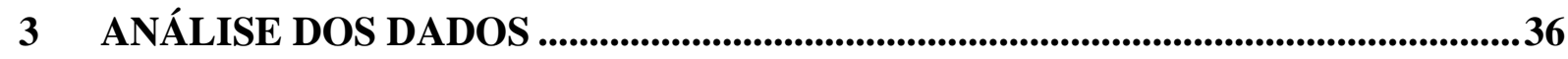

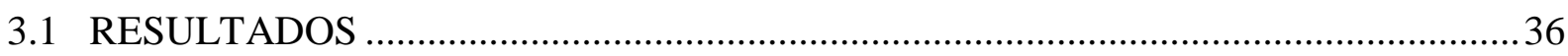

4 DISCUSS Ã

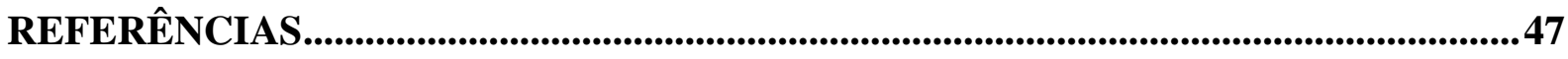

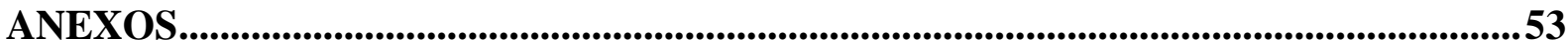

Anexo A - Termo de consentimento livre e esclarecido ..................................................54

Anexo B - Ficha de Identificação ...............................................................................56 
Para B. F. Skinner, precursor da abordagem analítico-comportamental, o comportamento humano é o resultado de processos de variação e seleção organizados didaticamente em três níveis diferentes que interagem entre si (Skinner, 1981).

O nível filogenético, referente a história evolutiva de uma espécie, influencia, por exemplo, no grau de suscetibilidade à aprendizagem dos seres humanos e no estabelecimento de comportamentos reflexos que possuem um valor de sobrevivência para a espécie. Foram os processos de variação e seleção no nível filogenético que possibilitaram a evolução de um aparato vocal que viabilizou a formação de ambientes sociais e culturais (Skinner, 1981).

O nível ontogenético se refere a história de aprendizagem do indivíduo durante sua vida. É neste nível que ocorre a seleção, manutenção e extinção do comportamento pelas consequências que este produz no ambiente. A este tipo de comportamento - selecionado por suas consequências -, Skinner deu o nome de operante (Skinner, 1981, 1953/2003).

Todorov (2002) discutiu o conceito de operante em uma análise histórica a partir de diferentes autores. Uma das definições apresentadas pelo autor é a de Schick (1971). Para Schick, o comportamento operante poderia ser definido por propriedades da resposta (seus efeitos, topografia e ocorrência na presença de certos estímulos). Outra definição trazida por Todorov é a de Catania (1996), que define operante como uma classe de comportamentos selecionada por suas consequências, neste contexto, todo comportamento pode ser visto sob os ângulos de sua estrutura (as propriedades formais), de sua função, e do desenvolvimento de estrutura e função. Catania apresenta diversas maneiras em que classes de operantes podem ser produzidas, como a modelagem, o esvanecimento e o estabelecimento de classes de ordem superior. Por fim, Todorov ressalta que chegamos ao ponto, na definição do conceito de operante, em que a estrutura do comportamento é vista como inevitavelmente determinada por por suas consequências. 
O terceiro nível de seleção é o cultural. Como nos outros dois níveis, a cultura também está inserida no modelo selecionista proposto por Skinner (1981), ou seja, há variações de determinadas práticas culturais que terão sua ocorrência alterada pelas consequências produzidas. Segundo Skinner (1981), a maneira como as pessoas de uma comunidade criam suas crianças, se divertem, se comunicam, se vestem etc. são as práticas de uma cultura. Quando falamos que determinada cultura é machista, por exemplo, estamos nos referindo a um conjunto de práticas que foram estabelecidas ao longo do tempo. Estas práticas culturais são transmitidas entre gerações e muitas vezes sevem como instrumento para que o indivíduo aprenda determinado repertório sem as especificidades da ontogenia, como o tempo e a exposição necessárias para o aprendizado de novos comportamentos (Micheletto, 1999).

Segundo Todorov (2012a), práticas culturais são mantidas por contingências socialmente determinadas que prevaleçam em uma sociedade, um grupo ou em uma organização. Estas contingências podem prevalecer por diferentes períodos. Praticamente todo comportamento operante humano poderia ser classificado como prática cultural, até mesmo comportamentos simples como comer, já que estes dependem de contingências que determinam o que comer e de que forma comer. Estes comportamentos são adquiridos por regras, exposição a modelos ou exposição direta a contingências.

A Análise do Comportamento é, portanto, uma ciência que se dedica ao estudo da interação entre comportamento e ambiente (Todorov, 2012c). Como ferramenta metodológica, utiliza-se de contingências que especificam relações funcionais entre eventos ambientais e comportamentos (Todorov, 2007).

O conceito de contingência possui uma importância central em qualquer discussão sobre o comportamento operante, seja em sua aplicação nas pesquisas sobre aprendizagem ou sobre problemas sociais relevantes. Algumas vezes este termo é utilizado como um sinônimo para "esquema de reforçamento", definindo as relações entre um estímulo discriminativo, uma 
resposta e uma consequência. De forma mais ampla, uma contingência descreve uma relação entre respostas e outros eventos (Lattal, 1995).

Mechner (2011) descreve uma série de vantagens no estudo do comportamento humano utilizando a contingência como ferramenta, como: a) a facilitação na apresentação gráfica de aspectos do comportamento; b) a identificação das variáveis que estão sendo manipuladas em determinado estudo; c) a comunicação concisa e sem ambiguidades entre pesquisadores da área; d) a categorização e classificação de áreas do conhecimento; e e) o suporte como ferramenta pedagógica para o ensino.

Skinner (1981), manifestou preocupações acerca dos problemas sociais vigentes, apontando a ciência, em especial a Análise do Comportamento, como uma excelente ferramenta para a análise e planejamento de práticas culturais benéficas para a humanidade. Neste sentido,

poderíamos esperar que seu modelo selecionista ressoasse nas Ciências Sociais (eg. Antropologia, Ciência Política, Economia), mas salvo raras exceções, como o antropólogo Marvin Harris, o diálogo entre a Análise do Comportamento e as ciências sociais ainda é limitado (Melo \& De Rose, 2012).

\subsection{METACONTINGÊNCIA}

Observando uma lacuna no estudo do terceiro nível de seleção, Sigrid Glenn, em 1986, cunhou o termo metacontingência para se referir a uma nova ferramenta conceitual destinada ao estudo de práticas culturais sob o enfoque analítico-comportamental. Inicialmente, o conceito foi definido como sendo uma unidade de análise que descreve relações funcionais entre classes de operantes, cada classe tendo consequências específicas e uma consequência comum em longo prazo para todos os operantes, porém, com a produção de novos trabalhos houve uma série de reformulações teóricas e empíricas (Azevedo, 2015; Andery \& Sério, 1999; 
Andery, Micheletto \& Sério, 2005; Glenn, 1986, 1988; Houmaar \& Rodrigues, 2006; Martone, 2008; Martone \& Todorov, 2007; Naves \& Vasconcelos, 2008; Todorov, 1987, 2009, 2010, 2012b, 2013; Vasconcelos, 2014; Vichi, 2004).

Todorov (2006) destaca que uma grande contribuição do trabalho pioneiro de Glenn (1986) para o estudo de práticas culturais está na forma inovadora de tratar o comportamento de grupos sem a dicotomia indivíduo vs. sociedade, encontrada nas ciências sociais. Isso torna possível abordar questões culturais sem precisarmos recorrer a outros níveis de linguagem. O conceito - por sua originalidade - permite o avanço nos estudos do terceiro nível de seleção do comportamento, sem desconsiderar o conhecimento produzido sobre o comportamento em grupos desenvolvido por outras áreas do conhecimento (Todorov, 2012b).

Com a publicação de novos trabalhos sobre metacontingências, surgiram alguns problemas conceituais referentes a falta de unidade entre os pesquisadores no uso do termo.

Todorov (2012b) aponta a utilização do conceito por pesquisadores para se referirem tanto a procedimento como a processos deles decorrentes e destaca a relação contingencial que há entre o produto agregado e as consequências culturais. Segundo o autor, é o produto agregado, e não as contingências comportamentais entrelaçadas que estão sendo selecionadas pela consequência. Uma metacontingência, então, descreve a relação entre um conjunto de contingências comportamentais entrelaçadas (CCE’s) necessárias para a formação de um produto agregado (PA) e de consequências providas por um ambiente cultural selecionador (Glenn \& Malott, 2004; Malott \& Glenn, 2006).

Dando destaque para a relação de dependência que há entre o PA e a consequência, Todorov (2012b) explica que:

Com relação ao operante, dizemos que a consequência de uma resposta seleciona uma classe. A consequência para o organismo seleciona uma classe de respostas. Com relação à metacontingência podemos dizer que a consequência seleciona um produto agregado, independentemente de variações nas CCEs. $O$ importante são as 
características do PA. Potencialmente $\boldsymbol{n}$ diferentes CCEs podem produzir o PA requerido pela metacontingência (p. 39).

Um produto agregado é o resultado de contingências comportamentais entrelaçadas que envolvem pelo menos duas pessoas (Todorov, 2010). Este produto poderia ser uma peça publicitária para uma loja de sapatos, por exemplo. Neste caso teríamos o entrelaçamento entre as contingências que mantém o comportamento de profissionais (o administrador da empresa, um especialista em design, um publicitário etc.) - onde o que um faz estabelece o contexto, e pode consequenciar o comportamento do outro e assim por diante - que juntos produzirão a peça (PA). Caso o lucro da loja aumente (consequência), podemos supor que a peça publicitária proposta será selecionada. Aliás, não só a peça, mas também o tipo de mídia produzido (televisiva, eletrônica, impressa etc.) e possivelmente os atores utilizados, o veículo escolhido para a divulgação, a agência de publicidade que participou do processo de criação e "n" outros aspectos envolvidos nesta metacontingência. Se em algum momento a empresa não alcançar o lucro prospectado, é provável que ocorra uma variação do modelo adotado. Neste caso, o conceito de metacontingência ajuda a explicar o fenômeno ocorrido, mas não exaure a explicação.

Martone e Todorov (2007) destacaram a importância das reformulações realizadas no conceito de metacontingência para que a abrangência dos fenômenos culturais possa ser abarcada e as contribuições advindas da tentativa de refinar o instrumental teórico da análise do comportamento. Com relação às ideias iniciais propostas por Glenn (1986), os autores identificaram três reformulações posteriores:

1) ênfase no processo seletivo do entrelaçamento de muitos operantes e, consequentemente, na transmissão de padrões comportamentais através do tempo; 2) a descrição das funções de diferentes efeitos ambientais produzidos pelo entrelaçamento; e 3) diferenciação entre processos de variação e seleção que ocorrem em nível individual (relações de macrocontingência) e processos de variação e seleção que ocorrem em nível cultural (relações de metacontingência) (p. 182). 
Uma metacontingência pode ser classificada de acordo com algumas de suas características. No artigo seminal da área, Glenn (1986) classificou as metacontingências em cerimoniais e tecnológicas. As primeiras envolvem comportamentos que são mantidos por reforços sociais derivados de status, posição social ou autoridade do agente reforçador, sem que haja relações diretas entre mudanças no ambiente ou benefícios para os indivíduos que estão se comportando. As segundas envolvem comportamentos mantidos por mudanças ambientais que não sejam arbitrárias. As consequências envolvidas nas metacontingências tecnológicas tem um valor utilitário para as pessoas que estão se comportando.

Além das classificações propostas por Glenn (1986) com base nos reforços envolvidos nas metacontingências, Todorov (2013) aponta outras possibilidades que poderiam ser aplicadas a partir de características do produto agregado. $\mathrm{O}$ autor sugere duas categorias: as metacontingências conservadoras, quando há pouca variabilidade nos comportamentos e no produto agregado envolvidos na metacontingência; e as metacontingências transformadoras, quando há a necessidade de que o produto agregado possua características originais, inovadoras.

Assim como ocorre com contingências individuais (Ferster \& Skinner, 1957), é possível estabelecermos vários esquemas de seleção cultural para produtos agregados, e alguns estudos já tem sido realizados neste sentido (Azevedo, 2015; Baia, 2008; Bullerjhann, 2009; Caldas, 2009; Costa, 2009; Martone, 2008; Nogueira, 2009; Pereira, 2008; Vasconcelos, 2014; Vichi, Andery, \& Glenn, 2009). Nas pesquisas de laboratório, o trabalho começa com a definição de metacontingência e são especificadas variáveis dependentes e independentes que sejam coerentes com a definição (Todorov, 2010).

A metacontingência também tem sido utilizada por alguns pesquisadores como ferramenta para analisar fenômenos sociais, tais como Leis (Todorov, 1987; Prudêncio, 2006; Martins, 2009; Carvalho, 2013; Cabral, 2014), dinâmica familiar (Naves \& Vasconcelos, 2008), 
intervenções culturais (Sénéchal-Machado \& Todorov, 2008), reeleição (Lamal \& Greenspoon, 1992) e processos históricos (Lamal, 1991; Rakos, 1991).

\subsection{TRABALHOS EXPERIMENTAIS}

O estudo de metacontingência tem obtido um suporte empírico cada vez maior (Azevedo, 2015; Amorim, 2010; Baia, 2008; Brocal, 2010; Bullerjhann, 2009; Caldas, 2009; Costa, Nogueira, \& Vasconcelos, 2012; Dos Santos, 2011; Gadelha, 2010; Neves, Woelz, \& Glenn; 2012; Oda, 2009; Ortu, Becker, Woelz, \& Glenn, 2012; Pereira, 2008; Vasconcelos, 2014; Vieira, 2010), sendo a Pontifícia Universidade Católica de São Paulo (PUC-SP), a Universidade Federal do Pará (UFPA) e a Universidade de Brasília (UnB), polos de produção de conhecimento no Brasil.

Dentre os procedimentos utilizados, o programa de computador Meta, desenvolvido por Thomas Woelz, e suas várias versões, tem sido utilizado principalmente em experimentos realizados por pesquisadores da PUC - SP (Amorim, 2010; Baia, 2008; Brocal, 2010; Bullerjhann, 2009; Caldas, 2009; Dos Santos, 2011; Gadelha, 2010; Oda, 2009; Pereira, 2008; Vieira, 2010). O programa possibilita o manejo de consequências individuais para comportamentos e consequências culturais ao longo de várias gerações de participantes.

Outro modelo de procedimento criado para o estudo experimental de metacontingências foi utilizado Vasconcelos (2014), com o programa "2 cavalos", desenvolvido por Todorov, Vasconcelos \& Costa (Vasconcelos, 2014), e Azevedo (2015), com o programa "Xadrez" (Todorov \& Vianney, 2013). Ambos os programas utilizaram procedimentos semelhantes que se destacam por sua simplicidade, baixo custo e por possibilitarem um bom controle experimental, já que é possível trabalhar somente com o nível cultural, sem manipular contingências individuais. 


\subsection{VARIABILIDADE}

O cientista Charles Darwin (1859/2004), ao trazer à tona sua teoria sobre seleção natural, abordou a importância da variação nos seres vivos para a manutenção de sua espécie, destacando que todo o ser que varia, tem maior probabilidade de sobreviver. De forma análoga, Skinner (1981) propõe um modelo selecionista para o estudo do comportamento humano, em que o comportamento é selecionado por suas consequências. Uma variação do comportamento pode produzir consequências que selecionarão.

Em ambos os modelos científicos, a seleção depende de aspectos ambientais para sua ocorrência, incluindo um substrato variável (Skinner, 1966, 1981). A variabilidade assume assim, um papel preponderante: sem variação não há seleção.

Enquanto Darwin destaca aspectos relativos à filogênese, partindo da formação genética dos indivíduos de uma espécie para mostrar que membros com características mais adequadas ao ambiente em que vivem tem maior probabilidade de sobreviverem e transmitirem estas propriedades através dos seus descendentes (Hull, Langman, \& Glenn, 2001), Skinner enfatiza aspectos relativos à ontogênese, ou seja, à história de aprendizagem dos indivíduos a partir de sua interação com o ambiente para descrever como ocorre a mudança no comportamento durante a vida de um indivíduo.

O comportamento operante apresenta algumas limitações temporais, já requer do organismo que ele se submeta às contingências ambientais a fim de que adquira determinados repertórios, e o tempo de uma vida de um ser humano as vezes é muito pequeno para determinados repertórios sejam estabelecidos. Essa limitação é parcialmente suprida por ambientes sociais e culturais, que fazem parte do que a Análise do Comportamento chama de terceiro nível de seleção (Micheletto, 1999). As práticas culturais de uma comunidade 
produzem certas consequências, e, assim como ocorre no comportamento operante, estas consequências interferem no surgimento, manutenção, transformação e extinção das práticas envolvidas (Todorov, 2012a).

Nas produções científicas, a variabilidade presente nos dados foi tida como indesejável diversas vezes, e apontada como decorrente de um controle experimental deficiente e de variáveis desconhecidas (Sidman, 1960). Para sanar lacunas teóricas e empíricas, analistas do comportamento tem se dedicado ao estudo da variabilidade per se (Hunziker \& Moreno, 2000; Abreu-Rodrigues, 2005), e as produções tem mostrado sistematicamente que a variabilidade comportamental pode estar relacionada com aspectos fisiológicos, como a utilização de drogas e problemas de desenvolvimento (Neuringer, 2004), pode ser induzida por certos eventos ambientais, como procedimentos de extinção (Antonitis, 1951), e também pode estar sendo mantida por controle operante (Page \& Neuringer, 1985).

A literatura analítico-comportamental atual relacionada à variabilidade segue duas frentes principais de investigação. A primeira se dedica a analisar a ocorrência de variabilidade como um subproduto de diferentes contingências de reforçamento (Hunziker \& Moreno, 2000).

Dentro desta linha, Antonitis (1951) desenvolveu um estudo pioneiro com um procedimento $\mathrm{ABA}$ em que submeteu ratos a diferentes contingências de reforçamento da resposta de focinhar uma barra horizontal em uma caixa experimental. Os ratos passaram por diferentes fases na seguinte ordem: nível operante, quando não havia nenhuma consequência programada para a resposta de tocar a barra com o focinho; FR 1, quando cada resposta era reforçada; e extinção, quando nenhum toque na barra era seguido de reforço. O critério para mensurar a variabilidade do comportamento dos ratos utilizado pelo autor foi a diversidade relativa aos pontos da barra tocados. As análises revelaram que esta variabilidade, em comparação com a primeira fase do experimento, foi reduzida pelo reforçamento e aumentou significativamente na fase de extinção. Outros autores também produziram dados que sugerem 
que a extinção pode aumentar os níveis de variabilidade, mesmo que este padrão comportamental não esteja sendo especificamente reforçado, ou seja, a variabilidade encontrada nos estudos não é uma variabilidade operante e sim induzida por condições ambientais (Eckerman \& Lanson, 1969; Lachter \& Corey, 1982; Schwartz, 1982).

A outra frente de investigação da variabilidade busca saber se há um aumento na frequência dos padrões variáveis quando o reforço é contingente a eles (Hunziker \& Moreno, 2000).

A variabilidade comportamental modelada e influenciada por consequências é chamada de variabilidade operante. Se comportar de forma não usual, variável ou imprevisível pode, algumas vezes, ser funcional. Entender este tipo de variabilidade nos ajuda a explicar aspectos importantes do comportamento humano, como fugir de predadores, caçar, resolver problemas, criar novos métodos experimentais etc. O reforçamento de variações no comportamento humano pode facilitar a aquisição de novas respostas pelo indivíduo (Denney \& Neuringer, 1998; Bizo \& Doolan, 2013), contribuindo para o que chamamos de criatividade, exploração e resolução de problemas. Alguns transtornos comuns em nossa sociedade, como o autismo, a depressão e o déficit de atenção e hiperatividade, contribuem para alterações anormais nos níveis de variabilidade, e o desenvolvimento de estudos sobre variabilidade operante podem ajudar compreender e alterar estes níveis quando necessário (Neuringer, 2002).

Schwartz (1980) realizou quatro experimentos a fim de verificar se a variabilidade comportamental poderia ter uma dimensão operante. Em seu primeiro experimento, o autor modelou a resposta de bicar de pombos em dois discos, esquerdo (E) e direito (D), de modo que a cada bicada uma luz se movia em uma matriz (5x5). As bicadas no disco E movimentavam a luz para a direita e as bicadas no disco D movimentavam a luz para baixo. A consequência era liberada quando a luz chegava no canto inferior direito, portanto, os pombos precisavam bicar 8 vezes para atingir o canto alvo, sendo 4 respostas no disco E e quatro respostas no disco 
D, o que permitia 70 combinações possíveis. As sequências com mais de quatro bicadas em um mesmo bico eram cancelas, com a luz retornando para a sua posição inicial no experimento, indicando o início de uma nova tentativa. A variabilidade do comportamento dos sujeitos foi analisada por meio da distribuição de respostas D e E nas sequências produzidas. Os dados do autor mostram uma estereotipia das respostas dos sujeitos, que - apesar das 70 combinações possíveis de sequências que produziriam reforço - mantinham uma sequência específica.

O segundo experimento (Schwartz,1980) apresentado mostrou um aumento na variabilidade de sequências emitidas e uma diminuição na taxa de respostas após um procedimento de extinção. No terceiro experimento o autor retirou a matriz de luz, o que produziu um aumento temporário na variabilidade das respostas, porém logo os sujeitos voltaram a emitir uma resposta estereotipada. No o quarto experimento, os pombos deveriam emitir uma sequência que fosse diferente da sequência anterior para que recebessem reforço um esquema que Schwartz denominou lag $n$ - e os dados obtidos mostraram que ainda assim os sujeitos emitiam prioritariamente uma única sequência específica.

Os dados obtidos levaram Schwartz a concluir que a variabilidade comportamental não poderia ser reforçada diretamente, com a ressalva de que a tarefa do experimento poderia ser muito difícil ou que a história experimental dos sujeitos, que já tinham estabelecido padrões de estereotipia, poderia ter dificultado a mudança de padrões de resposta. Para tentar responder a esta última possibilidade, Schwartz (1982) repetiu o experimento quatro com sujeitos ingênuos e obteve resultados bem próximos, com sequências estereotipadas e pouca variabilidade.

Page e Neuringer (1985) retomaram as análises de Schwartz (1982) e realizam 6 experimentos. Os dois primeiros experimentos foram bem próximos aos experimentos realizados por Schwartz (1982). O Experimento 3 manipulou permitiu descobrir que os pombos produziram uma grande quantidade de padrões variáveis, mesmo quando a resposta deveria ser diferente das cinquenta últimas respostas dadas. O Experimento 4 manipulou o número de 
respostas por tentativa e descobriu que a variabilidade aumentou junto com o aumento de respostas por tentativas, indicando que o pombo estava respondendo de forma quase aleatória. O Experimento 5 mostrou que para altos níveis de variabilidade serem estabelecidos, o reforçamento deve ser contingente a resposta de variabilidade. E, por fim, o Experimento 6 demonstrou um controle de estímulos em que os pombos produziam um padrão variável enquanto uma luz vermelha estava acesa e sob uma luz azul, os pombos repetiam um padrão fixo. Os resultados dos experimentos 3,4,5 e 6 mostraram que a variabilidade comportamental poderia ser diretamente reforçada.

Desde então foram desenvolvidos vários outros estudos em que comportamentos que apresentavam certo nível de variabilidade foram reforçados (Barba \& Hunziker, 1981; Cohen, Neuringer, \& Rhodes, 1990; Cruvinel \& Sério, 2008; Denney \& Neuringer, 1998; Hunziker, Caramori, Silva, \& Barba, 1998). E, embora não haja um padrão entre os conceitos e os métodos utilizados, os autores estabelecem um referencial comparativo para que mudanças ou diferenças entre comportamentos possam ser medidas nas análises realizadas (Barba, 2010).

Dentre os procedimentos utilizados nos estudos sobre variabilidade operante, temos o lag n, uma contingência de reforçamento em que a resposta deve ser diferente de " $n$ " respostas anteriores, sendo que esta diferença se refere a propriedades (localização, duração, intervalo entre respostas) da resposta que será estudada (Schwartz, 1980; Barba, 2010). A contingência lag $n$ pode operar sobre quaisquer unidades de comportamento, como pressões a barra (ratos) ou bicadas sobre discos (pombos). Também podem haver outros parâmetros para análise, como o intervalo de tempo que separa duas pressões à barra consecutivas (Schoenfeld, Harris, \& Farmer, 1966), ou ainda parâmetros configurativos referentes à resposta que deve ser emitida (Barba, 2010).

Para medir a variabilidade, Page e Neuringer (1985) utilizaram um índice oriundo da teoria da informação, o índice estatístico U (Attneave, 1959). Muitos outros trabalhos 
recorreram aos mesmos índices posteriormente (Barba \& Hunziker, 2003; Hunziker, Saldana, \& Neuringer, 1996; Neuringer, 1992; Neuringer \& Huntley, 1992). Os experimentos realizados por Page e Neuringer (1985) manipularam esquemas que reforçavam diferencialmente a emissão de sequências formadas pelos componentes E e D. Essas sequências continham um número " $x$ " de elementos constituintes. $\mathrm{O}$ valor de " $\mathrm{x}$ " determina o número total configurações distintas possíveis. Se uma sequência é formada por quatro elementos, por exemplo, têm-se 16 $\left(2^{4}\right)$ configurações possíveis. Ao final da sessão experimental, foi possível obter o conjunto das sequências emitidas e calcular a frequência relativa em que foi emitida cada uma das diferentes sequencias, podendo-se verificar, portando, uma distribuição das frequências em que ocorria cada uma das configurações. $\mathrm{O}$ índice $\mathrm{U}$ foi calculado com base nos valores de frequência relativa e refletiu a uniformidade dessa distribuição. Caso o sujeito emitisse apenas uma das diferentes configurações, o índice U apresentaria o seu valor mínimo “ 0 ”. E se o sujeito emitisse com frequência idêntica todas as configurações possíveis, o índice U apresentaria o valor máximo "1" (Barba, 2010).

A fim de investigar o efeito do momento de exposição à contingência de variação sobre a manutenção da variabilidade comportamental, Stokes e Balsam (2001) realizaram um experimento com humanos utilizando uma contingência lag n. Os participantes foram divididos em quatro grupos. A tarefa consistia em mover uma luz da parte superior para a parte inferior de uma pirâmide durante três fases. Para o Grupo I, um critério lag 25 foi introduzido na primeira fase de 50 tentativas; para o Grupo II, na segunda fase; e, para o Grupo III, na quarta. Foi constatado que a contingência lag aumentou a variabilidade comportamental, porém cada grupo apresentou índices de variabilidade distintos quando a contingência não era mais apresentada. Os resultados indicaram que a manutenção da variabilidade é maior quando a contingência lag é introduzida em fases iniciais da aprendizagem e após a aquisição de um repertório básico para a realização da tarefa. 
Buscando responder questões relativas ao terceiro nível de seleção, alguns trabalhos experimentais que utilizam como recurso o conceito de metacontingência, analisaram a variabilidade de determinados aspectos das metacontingências programadas, sem que a variabilidade estivesse sendo especificamente consequenciada (Azevedo, 2015; Bullerjhann, 2009; Caldas, 2009; Dos Santos, 2011; Vasconcelos, 2014), mostrando que a variabilidade também é uma dimensão das práticas culturais.

Vasconcelos (2014), realizou dois experimentos com o programa "2 Cavalos", desenvolvido por Todorov, Vasconcelos \& Costa (Vasconcelos, 2014), que envolviam cinco condições experimentais dividas em 10 fases: a) linha de base; b) modelagem; c) extinção sinalizada e d) remodelagem. A metacontingência trabalhada era composta por contingências comportamentais entrelaçadas (o comportamento de cada participante era condição para o comportamento do outro e para a formação do produto agregado), produto agregado (o encontro de duas peças que se moviam em "L" em um tabuleiro virtual de xadrez) e consequência (o feedback emitido pelo programa na tela do computador). Para analisar a variabilidade do local de encontro das peças no tabuleiro, foi utilizado um índice de dispersão. Os resultados dos experimentos realizados corroboram com a literatura de variabilidade em contingências individuais (Antonitis, 1951), já que houve maior variação nas fases de linha de base, em que não havia consequências, e na fase de extinção sinalizada. E nas fases de modelagem e remodelagem foi possível observar uma estereotipia na localização do produto agregado, embora a estereotipia não fosse exigida.

Dos Santos (2011), utilizando o programa de computador "Meta", desenvolvido por Thomas Woelz, investigou os fenômenos envolvidos na seleção, recorrência e transmissão de práticas culturais e aspectos que poderiam ser responsáveis por produzir variação ou estereotipia nas contingências comportamentais entrelaçadas necessárias para a formação do produto agregado requerido pelo procedimento. Foram realizados dois experimentos baseados 
em trabalhos anteriores (Bullerjhann, 2009; Caldas, 2009; Pereira, 2008), com algumas pequenas alterações. A variabilidade foi medida a partir da frequência da produção de bônus pelos participantes. No primeiro experimento, apenas um procedimento de correção - comum a estes experimentos - foi retirado, e os resultados obtidos mostraram que a estereotipia das contingências comportamentais entrelaçadas encontrada em estudos anteriores se manteve. No segundo experimento, houve uma realocação dos participantes a cada troca de geração. Apesar da troca da posição dos participantes, os resultados ainda indicaram certa estereotipia, porém com índices menores do que no primeiro experimento. A autora ressaltou a importância de investigar quais fenômenos podem estar envolvidos na produção de estereotipia em situações experimentais que envolvem metacontingências e a possibilidade de testar outras manipulações que poderiam produzir maior variabilidade nas respostas apresentadas pelos participantes.

Seguindo a mesma linha dos estudos que utilizam o programa Meta (Bullerjhann, 2009; Caldas, 2009; Pereira, 2008), Kracker (2013) realizou três experimentos para investigar os efeitos de esquemas lag $n$ e crf (reforçamento contínuo) em relação à variabilidade comportamental em processos de seleção cultural e para averiguar de que maneira uma maior ou menor variabilidade ao longo desses processos afetariam a seleção de uma nova metacontingência diante de uma mudança no critério de apresentação das consequências culturais.

O Experimento I (Kracker, 2013) foi realizado com 21 participantes ao longo de 17 gerações onde vigoraram esquemas análogos ao lag 2 e lag 1. Cada geração era composta por três participantes, sendo que um destes era trocado na geração subsequente. $\mathrm{O}$ critério de encerramento da geração era a produção de bônus - liberados de forma contingente ao padrão variável das contingências comportamentais entrelaçadas - em $80 \%$ dos 10 últimos ciclos, ou atingir o total de 20 ciclos, independentemente da produção de bônus. Foram encontradas algumas dificuldades para que o critério de estabilidade fosse atingido durante o primeiro 
experimento, o que levou a pesquisadora a realizar mudanças nos critérios de variabilidade durante a realização da atividade. No Experimento II foi utilizado como um controle e não houve uma contingência lag n. No Experimento III foi implementada uma contingência lag 1, onde a manutenção e transmissão sistemática do padrão de variabilidade das contingências comportamentais entrelaçadas pôde ser observada a partir da $13^{\mathrm{a}}$ geração. Os resultados destes experimentos (Kracker, 2013) apontam dificuldades em conseguir estabelecer e manter o padrão de variação das contingências comportamentais entrelaçadas nos experimentos I e III, porém o padrão de variação foi estabelecido sistematicamente durante as últimas gerações do experimento III, com destaque para as duas últimas gerações, quando houve a produção de bônus em todos os ciclos das gerações, mostrando que a variabilidade estava sendo mantida pela contingência em vigor, e não induzida por outros aspectos da condição experimental.

Kracker (2013) sugere que a dificuldade em alcançar os padrões de variação em seus experimentos esteja relacionada à complexidade das contingências comportamentais entrelaçadas necessárias para a produção de bônus (produto agregado), já que havia critérios sobrepostos: A combinação específica da soma dos números digitados pelos três participantes de cada geração nos espaços programados e a necessidade de apresentar somas individuais diferentes às somas do ciclo anterior, de acordo com a contingência lag vigente.

A fim de trazer novas contribuições sobre a variabilidade de práticas culturais, tendo em vista a importância da área e a pequena quantidade de material publicado sobre o assunto, o presente estudo tem como objetivo investigar o estabelecimento de padrões de variabilidade em uma metacontingência lag n.

Buscou-se verificar se é possível produzir padrões variáveis nos produtos agregados de uma metacontingência, mantidos por consequências sociais, seguindo um procedimento similar ao realizado nos experimentos de Vasconcelos (2014) e Azevedo (2015). 
A partir do programa de computador "Xadrez" (versão 7.3), desenvolvido por Todorov e Vianney (2013), foram realizados três experimentos que variaram conforme o número de fases e o critério para a mudança de uma fase para outra. O Experimento I foi composto por quatro fases: Linha de Base, Lag 1, Lag 2 e Extinção. O Experimento II foi composto por cinco fases: Linha de Base, Lag 1, Lag 2, Extinção e Retorno à Linha de Base. E o Experimento III contou com seis fases: Linha de Base, Lag 1, Lag 2, Lag 3, Extinção e Retorno à Linha de Base.

A metacontingência do experimento pode ser descrita nos seguintes termos: 1) CCE's: o comportamento de cada participante é condição essencial para o comportamento do outro e para a formação do produto agregado, tal como numa situação de cooperação; 2) Produto Agregado: o encontro das duas peças no tabuleiro virtual do programa e 3) Consequência: o feedback emitido pelo programa para cada produto agregado satisfatório.

Neste trabalho, foi considerada a variabilidade da localização do produto agregado (encontro das peças) dentro do tabuleiro virtual. Uma localização diferente ocorria quando ao menos um dos participantes estava localizado em uma célula diferente do encontro anterior. Para verificar se houve diferenças entre as fases, foram analisadas a quantidade de partidas realizadas pelas duplas em cada fase dos experimentos, a quantidade de movimentos realizados pelas duplas em cada fase dos experimentos e os valores do índice estatístico U referentes a variabilidade da localização dos produtos agregados no tabuleiro.

Foram realizadas replicações intrasujeitos e a exposição de participantes a condições sem a exigência de variação e com diferentes exigências de variação ( lag 1, lag 2 e lag 3), exigindo, potencialmente, maiores níveis de variabilidade em relação aos estudos anteriores (Dos Santos, 2011; Kracker, 2013). A tarefa dada aos participantes também é simplificada, o que pode ser uma vantagem em termo de controle experimental, permitindo maior precisão. 


\section{MÉTODO}

\subsection{PARTICIPANTES}

Participaram da pesquisa 16 estudantes universitários do curso de Psicologia de uma universidade particular de Brasília - DF que não declararam não terem tido contato anterior com pesquisas que utilizassem o mesmo procedimento deste trabalho (Anexo B). Os participantes foram convidados diretamente em sala de aula. Aqueles que aceitaram participar, assinaram uma lista com o nome, contato e os horários disponíveis. Os participantes formaram oito duplas, sendo que quatro participaram do Experimento I, duas participaram do Experimento II e duas duplas participaram do Experimento III. As duplas foram formadas pelo pesquisador a partir da disponibilidade de data e horário dos participantes, e foram contatadas por telefone para que a sessão experimental fosse agendada.

Antes do início do experimento os participantes foram solicitados a assinarem o Termo de Consentimento Livre e Esclarecido (Anexo A) entregue pelo experimentador e uma ficha de identificação (Anexo B) caso desejassem receber o texto final do estudo.

\subsection{MATERIAIS E INSTRUMENTOS}

A coleta de dados foi realizada em uma sala de aula equipada com mesa e cadeiras dispostas lado a lado. O computador onde a tarefa foi realizada ficou posicionado em uma mesa com duas cadeiras para os membros da dupla, e, no lado oposto aos participantes, havia uma cadeira para o pesquisador.

Para a realização da atividade, foi utilizado um notebook Dell com processador Intel Core i7, 8GB de memória RAM, sistema operacional Microsoft Windows ${ }^{8} 8$ Home Basic. O 
notebook foi equipado com o programa "Xadrez", versão 7.3, desenvolvido por Todorov e Vianney (2013), que permite que os participantes movimentam suas peças em "L" (como a peça "cavalo" em um jogo de xadrez tradicional) por um tabuleiro virtual de tamanho 8x8, com 64 células (Figura 1). Há somente duas peças no jogo, uma para cada participante, e o objetivo é promover o encontro destas peças no tabuleiro virtual seguindo um parâmetro específico. São necessários no mínimo quatro movimentos por dupla para que as peças se encontrem e não há limite de movimentos por partida. A partida tinha início com as peças localizadas no canto superior esquerdo e inferior direito do tabuleiro e se encerrava quando as peças se encontravam lado a lado, na horizontal, vertical ou em diagonal. Em virtude do número de células e da configuração dos encontros, é possível um total de 840 encontros diferentes no tabuleiro.

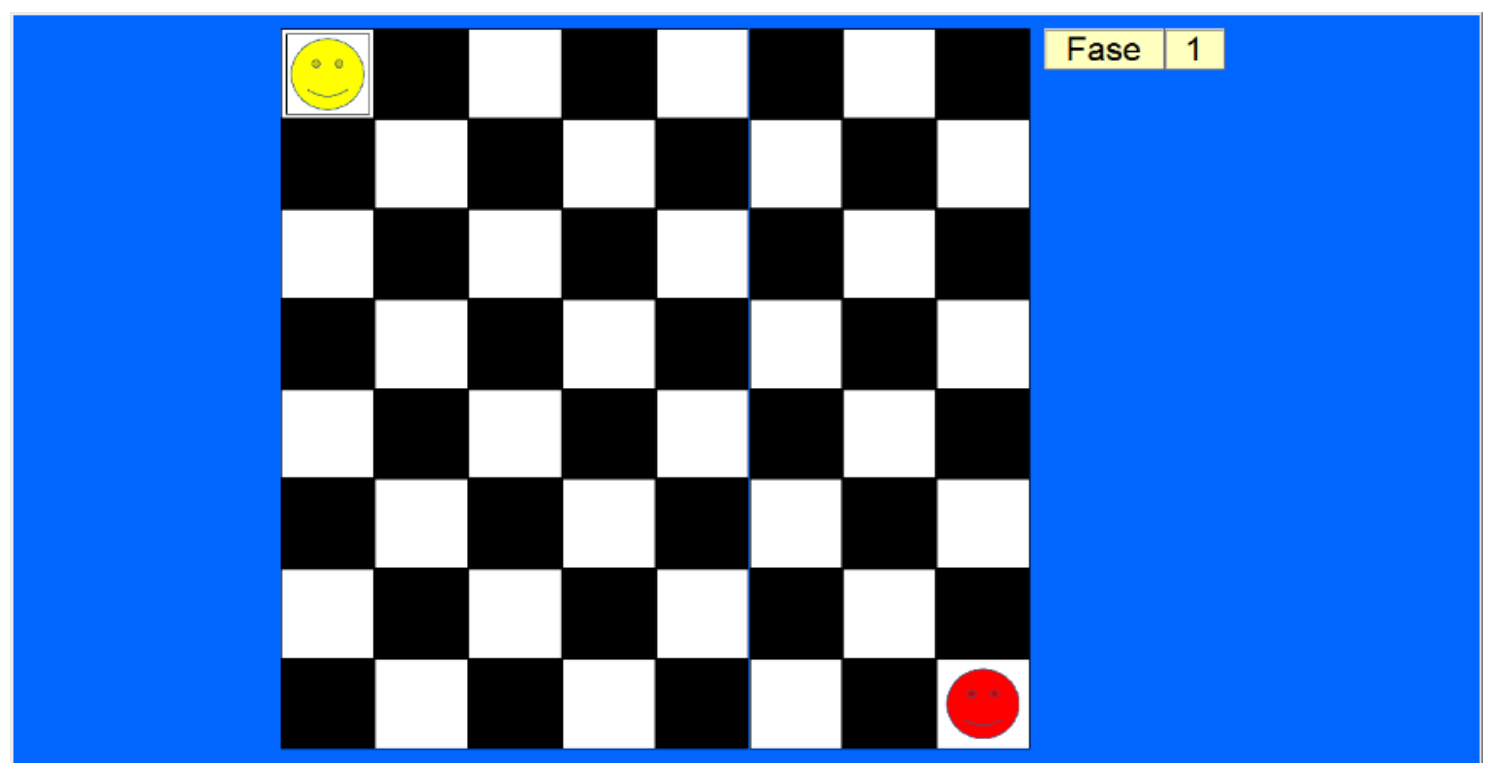

Figura 1 - Tabuleiro do programa "Xadrez" (Todorov \& Vianney, 2013) visível aos participantes.

Para os experimentos, foram programadas uma fase de linha de base, fases em que uma contingência lag poderia ser inserida, uma fase de extinção e uma fase de retorno à linha de base. A utilização e configuração destas fases variaram conforme o experimento realizado.

Os resultados foram gerados em um output no próprio programa, mostrando o número de partidas em cada fase, a quantidade de partidas em que houve reforço, a quantidade de 
movimentos em cada partida, o tempo gasto em cada fase e a localização das peças no tabuleiro durante os movimentos e encontros (Figuras 2 e 3 ).

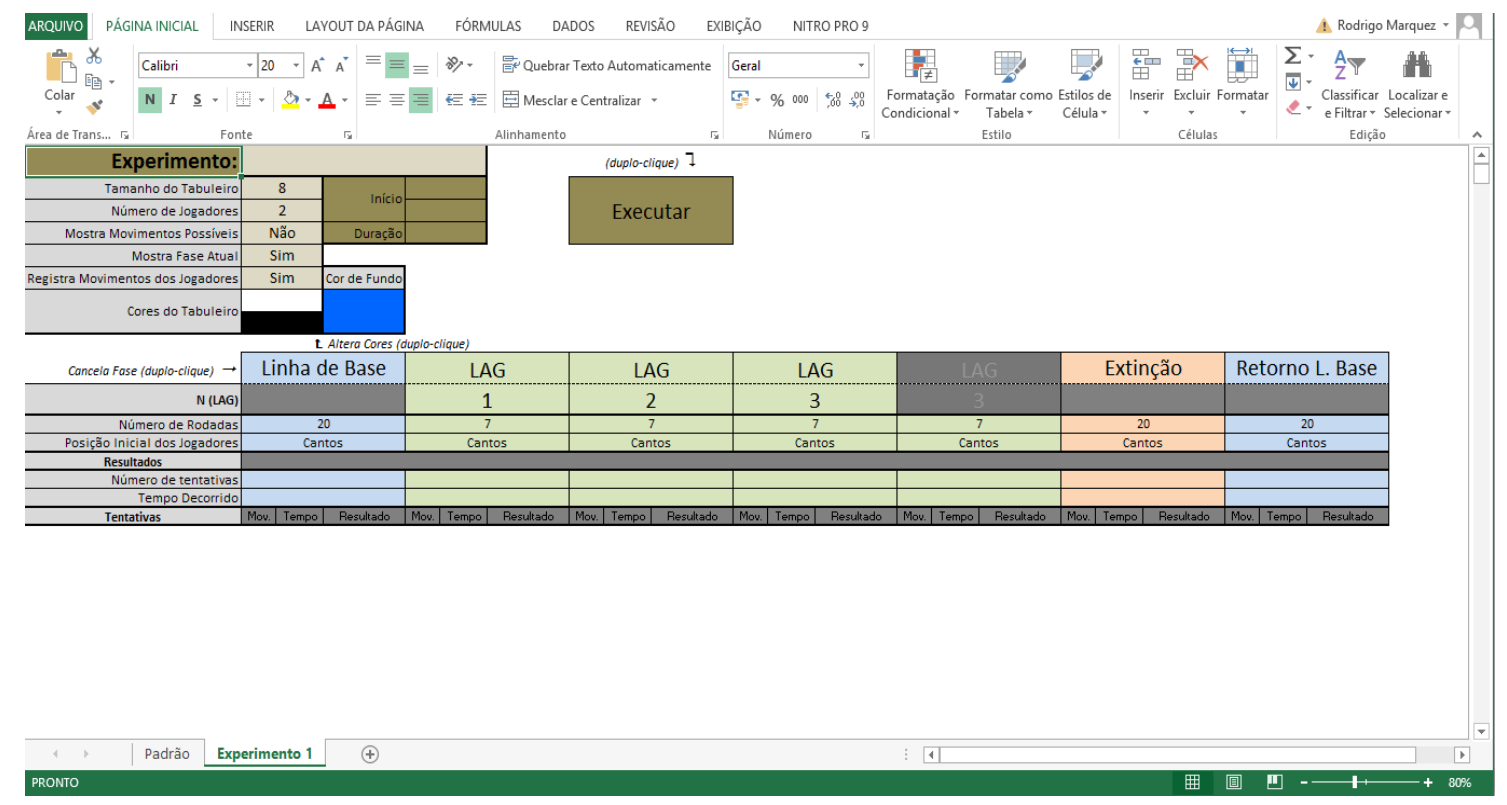

Figura 2 - Output visível ao pesquisador. As fases poderiam ser ativadas ou desativadas com dois cliques nas células "LINHA DE BASE", "LAG", "EXTINÇÃO" e "RETORNO L. BASE". 


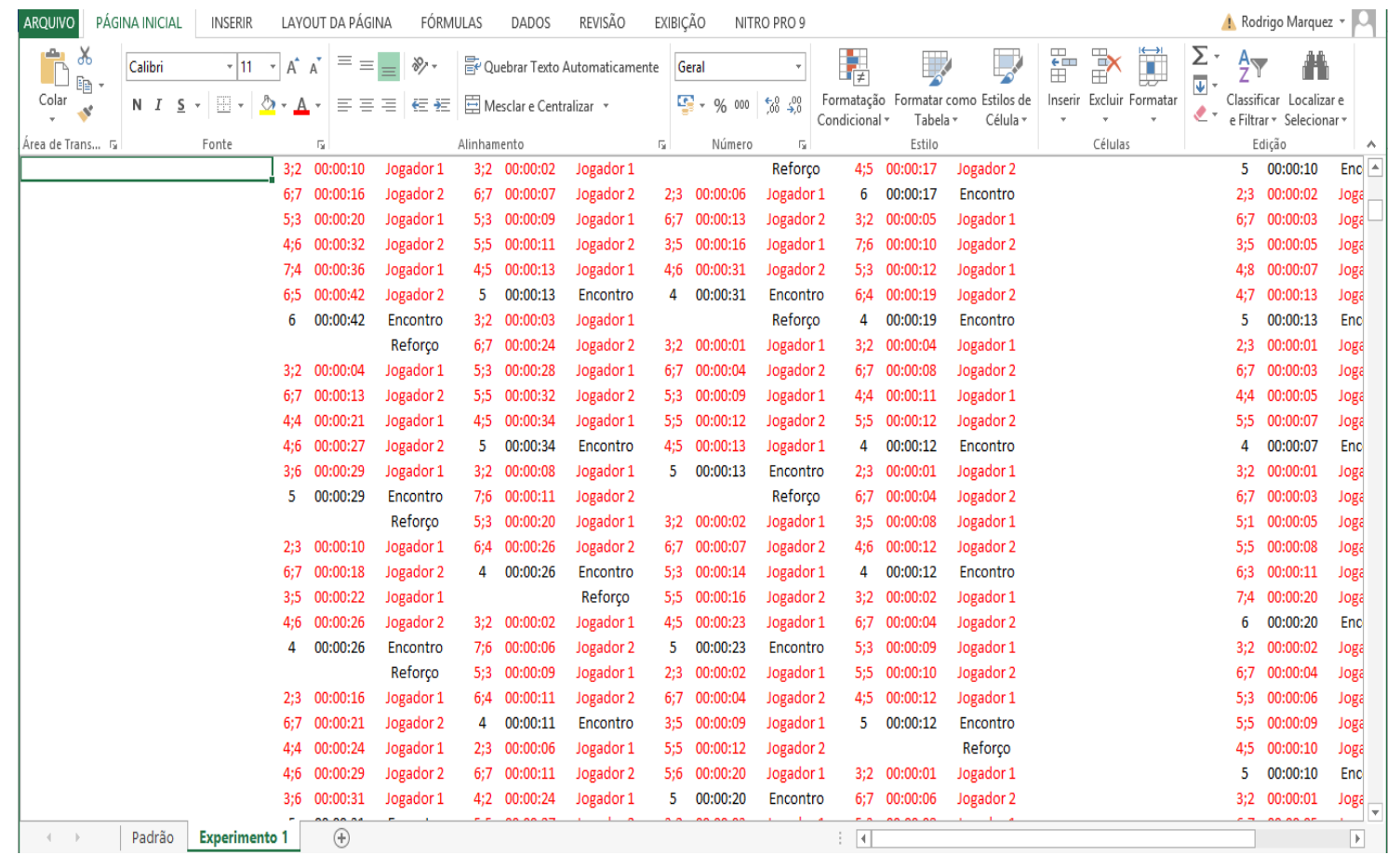

Figura 3 - Dados dispostos no output para o pesquisador. Os dois primeiros números das linhas em vermelho se referem à localização das peças no tabuleiro na jogada. Os seis números seguintes se referem aos segundos necessários até a realização da jogada. Os termos "jogador 1" e "jogador 2" identificam quem realizou a jogada. O primeiro número em preto se refere ao total de jogadas realizadas. Os seis números seguintes em preto se referem ao total de segundos gastos na partida. Em seguida o programa registra "Encontro Reforço" se os critérios da fase foram atingidos, ou somente "Encontro", se os critérios não foram atingidos.

\subsection{PROCEDIMENTO}

Cada dupla participou de apenas um experimento realizado no estudo e apenas uma vez. Ao entrarem na sala de coleta, os participantes foram orientados sobre a pesquisa, receberam o Termo de Consentimento Livre e Esclarecido (TCLE) e os que tinham interesse em receber informações posteriores sobre o estudo, preencheram uma ficha de identificação. Após a dupla ser posicionada em frente ao computador, foram entregues uma folha de papel para cada participante com as seguintes instruções:

Olá!

A partir de agora, vocês realizarão uma atividade juntos. Este jogo tem um caráter cooperativo, portanto, vocês estão jogando juntos e não um contra o outro. Cada jogador terá uma "carinha" no tabuleiro e deverá movimentá-la através de clicks no mouse. Para movê-la, basta dar um toque em cima da célula que deverá receber a peça. 
Cada "carinha" move-se fazendo um ' $L$ ' em qualquer direção. O movimento em ' $L$ ' move a peça por 3 casas em cada jogada (por exemplo, uma casa para frente e duas para o lado). Uma rodada começa com a peça de cada jogador localizada nos extremos do tabuleiro. O jogador que ficar com a peça do extremo superior esquerdo sempre começa as rodadas. Os jogadores movem suas peças alternadamente. O objetivo do jogo é que as peças se encontrem no tabuleiro virtual de acordo com um padrão específico. As peças não ocupam a mesma célula e o encontro pode ocorrer em qualquer posição (horizontal, vertical ou diagonal). Ao final de cada partida, caso ela tenha sido bem sucedida, vocês receberão a mensagem: "PARABÉNS! O objetivo foi alcançado!". Clique na mensagem para começar uma nova rodada.

A duração do experimento dependerá do desempenho de vocês. O programa informará quando o jogo chegar ao fim. Mas, vocês podem encerrar o experimento a qualquer momento, caso desejem.

Em caso de dúvidas, releiam as instruções! Vocês podem consulta-las em qualquer momento durante a atividade. É permitido conversar durante as rodadas do jogo. Mas se mantenham atentos à tarefa e evitem conversar sobre assuntos não relacionados à atividade.

Decidam quem ficará com cada peça do tabuleiro. Cada jogador deve continuar com a mesma peça até o fim do jogo.

Quando estiverem prontos, cliquem na tela para começar.

Não houve instruções adicionais e em caso de dúvidas os participantes foram instruídos a ler a folha com as instruções novamente.

Haja vista as dificuldades encontradas por Kracker (2013) para atingir os critérios de variação de seu estudo, o pesquisador optou por aumentar gradativamente o valor do "n" das fases em que vigorou uma contingência lag. Para melhorar as condições de análises do trabalho, houve um aumento no número fixo de partidas da fase "Linha de Base" nos Experimentos II e III, além do acréscimo da fase "Retorno à Linha de Base. No Experimento III foi acrescentada uma fase a mais com a contingência lag, a fim de analisar outro nível da VI.

A consequência programada pelo pesquisador consistia na apresentação da mensagem "PARABÉNS! O objetivo foi alcançado!" (Figura 4) quando havia a produção do produto agregado de acordo com os critérios da fase. Nas fases com uma contingência lag, como previsto nos experimentos com variabilidade, os primeiros encontros eram reforçados. 


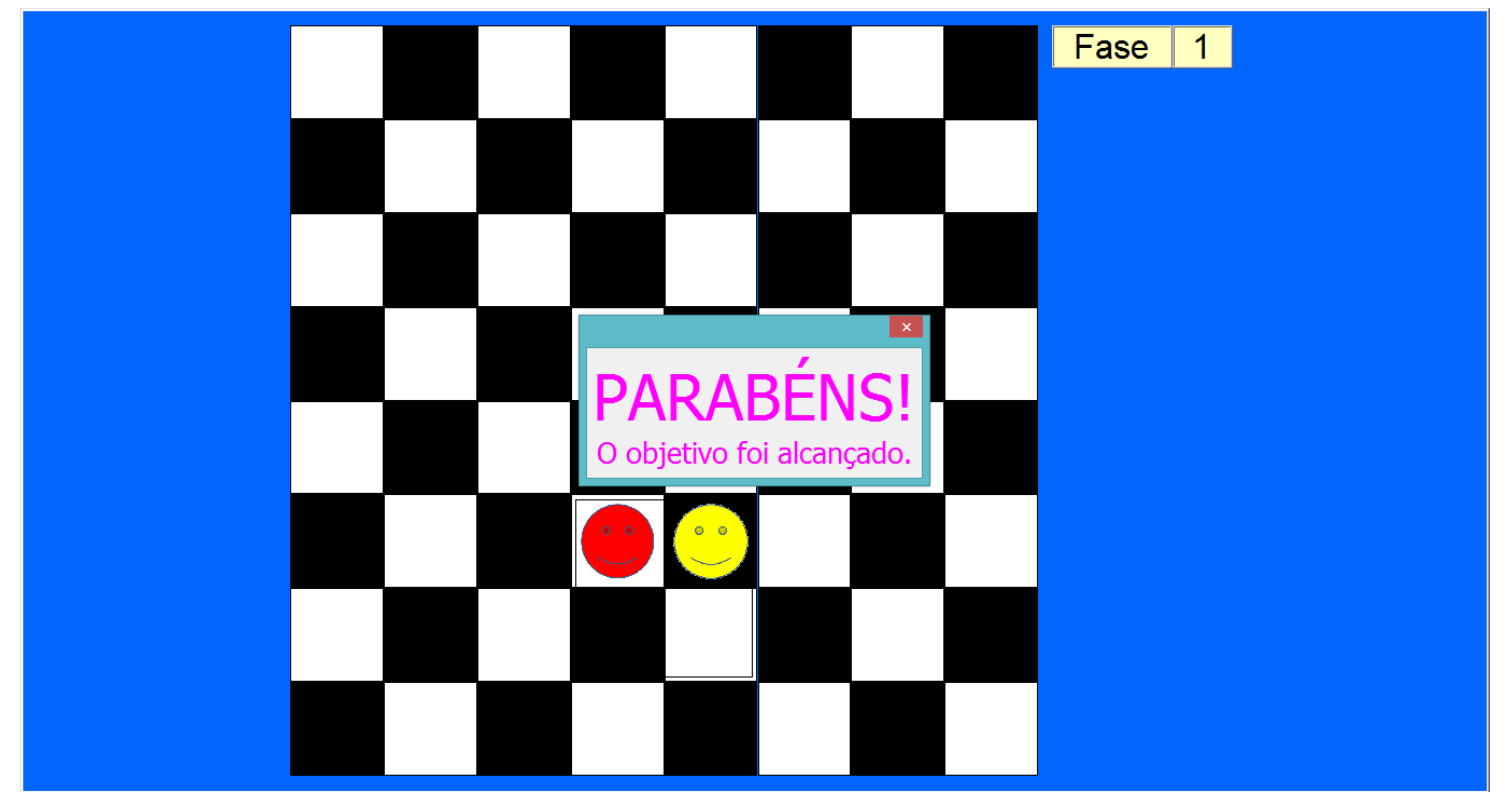

Figura 4 - Apresentação da consequência social programada na tela do computador

As duplas foram identificadas por números, em que o número anterior ao “.” se refere ao experimento pelo qual a dupla passou, e o número posterior ao “.” identifica a dupla a qual pertence os dados.

No Experimento I, houve quatro fases: Linha de Base, Lag 1, Lag 2 e Extinção, descritas abaixo.

Linha de base: Nesta primeira fase o encontro das peças poderia ocorrer em qualquer ponto do tabuleiro virtual e todos os encontros foram consequenciados. O critério para que uma nova fase fosse iniciada eram 10 partidas.

Lag 1: Em uma metacontingência lag n foi necessário que o produto agregado produzido pela dupla seja diferente do produto produzido em $\mathrm{n}$ partidas anteriores para que ele seja reforçado. Nos experimentos, um produto agregado era considerado variado quando ele ocorria em células diferentes dos produtos agregados de n partidas anteriores. Nesta fase, como previsto em um esquema lag 1, a consequência programada (mensagem "PARABÉNS! O objetivo foi alcançado!") só aparecia na tela do programa quando o produto agregado fosse diferente do produto agregado da partida imediatamente anterior. Caso os participantes não cumprissem o 
critério de variação estabelecido, a mensagem: "Fim da Partida" era apresentada e as peças dos jogadores retornavam as suas posições iniciais, sinalizando uma nova partida. A fase se encerrava quando os produtos agregados atingiam o critério de variação (lag 1) durante sete partidas consecutivas.

Lag 2: Nesta fase, como previsto em um esquema lag 2, a consequência programada era emitida quando o produto agregado fosse diferente dos produtos agregados das duas partidas anteriores. Assim como na fase "lag 1", caso os participantes não cumprissem o critério de variação estabelecido em cada partida, a mensagem: "Fim da Partida" era apresentada e as peças dos jogadores retornavam as suas posições iniciais, sinalizando uma nova partida. A fase se encerrava quando os produtos agregados atingiam o critério de variação (lag 2) durante sete partidas consecutivas.

Extinção: Nesta fase havia um número fixo de 20 partidas sem que houvesse consequência para o produto agregado. Ao final das 20 partidas a mensagem: "Fim!", aparecia na tela do computador.

O Experimento II foi similar ao experimento I, exceto pelo aumento de partidas da fase "Linha de Base", que passou de 10 para 20, e o acréscimo da fase "Retorno à Linha de Base" após a fase "Extinção". A fase "Retorno à Linha de Base" teve um número fixo de 20 partidas. O encontro das peças poderia ocorrer em qualquer ponto do tabuleiro virtual e todos os encontros foram consequenciados com a consequência programada. Ao final desta fase, a mensagem: "Fim!", aparecia na tela do computador, como acontecia anteriormente na fase “extinção".

O Experimento III foi similar ao Experimento II, com apenas uma alteração. Foi acrescentada a fase "lag 3" após a fase "lag 2" e antes da fase "extinção". Como previsto em um esquema lag 3, a consequência programada era emitida quando o produto agregado fossediferente dos produtos agregados das três partidas anteriores. Os outros critérios se 
mantiveram. Um resumo da descrição das fases em cada experimento pode ser encontrado no

Quadro 1.

Quadro 1 - Descrição das fases dos experimentos

\begin{tabular}{|c|c|}
\hline \multicolumn{2}{|c|}{ Experimento I } \\
\hline Linha de base & $\begin{array}{l}\text { Dez partidas (número fixo), sendo todos os } \\
\text { encontros reforçados. }\end{array}$ \\
\hline Lag 1 & $\begin{array}{l}\text { A consequência programada era emitida quando o } \\
\text { produto agregado fosse diferente do produto } \\
\text { agregado anterior. A fase se encerrava após o } \\
\text { produto agregado variar conforme o esquema LAG } \\
1 \text { durante sete partidas consecutivas. }\end{array}$ \\
\hline Lag 2 & $\begin{array}{l}\text { A consequência programada era emitida quando o } \\
\text { produto agregado fosse diferente do produto } \\
\text { agregado anterior. A fase se encerrava após o } \\
\text { produto agregado variar conforme o esquema LAG } \\
2 \text { durante sete partidas consecutivas. }\end{array}$ \\
\hline Extinção & $\begin{array}{l}20 \text { partidas (número fixo) sem que houvesse } \\
\text { consequência para o produto agregado. Ao final da } \\
\text { vigésima partida, a mensagem: "Fim!" aparecia na } \\
\text { tela do computador indicando o fim do } \\
\text { experimento. }\end{array}$ \\
\hline \multicolumn{2}{|c|}{ Experimento II } \\
\hline Linha de Base & $\begin{array}{l}20 \text { partidas (número fixo), sendo todos os } \\
\text { encontros reforçados. }\end{array}$ \\
\hline Lag 1 & $\begin{array}{l}\text { A consequência programada era emitida quando o } \\
\text { produto agregado fosse diferente do produto } \\
\text { agregado anterior. A fase se encerrava após o } \\
\text { produto agregado variar conforme o esquema LAG } \\
1 \text { durante sete partidas consecutivas. }\end{array}$ \\
\hline Lag 2 & $\begin{array}{l}\text { A consequência programada era emitida quando o } \\
\text { produto agregado fosse diferente do produto } \\
\text { agregado anterior. A fase se encerrava após o } \\
\text { produto agregado variar conforme o esquema LAG } \\
2 \text { durante sete partidas consecutivas. }\end{array}$ \\
\hline Extinção & $\begin{array}{l}20 \text { partidas (número fixo) sem que houvesse } \\
\text { consequência para o produto agregado. }\end{array}$ \\
\hline Retorno à Linha de Base & $\begin{array}{l}20 \text { partidas (número fixo), sendo todos os } \\
\text { encontros reforçados. Ao final da vigésima partida, } \\
\text { a mensagem: "Fim!" aparecia na tela do } \\
\text { computador indicando o fim do experimento. }\end{array}$ \\
\hline \multicolumn{2}{|c|}{ Experimento III } \\
\hline Linha de Base & $\begin{array}{l}20 \text { partidas (número fixo), sendo todos os } \\
\text { encontros reforçados. }\end{array}$ \\
\hline Lag 1 & $\begin{array}{l}\text { A consequência programada era emitida quando o } \\
\text { produto agregado fosse diferente do produto } \\
\text { agregado anterior. A fase se encerrava após o } \\
\text { produto agregado variar conforme o esquema LAG } \\
1 \text { durante sete partidas consecutivas. }\end{array}$ \\
\hline
\end{tabular}


Quadro 1 - Continuação

\begin{tabular}{|l|l|}
\hline Lag 2 & $\begin{array}{l}\text { A consequência programada era emitida quando o } \\
\text { produto agregado fosse diferente do produto } \\
\text { agregado anterior. A fase se encerrava após o } \\
\text { produto agregado variar conforme o esquema LAG } \\
\text { 2 durante sete partidas consecutivas. }\end{array}$ \\
\hline Lag 3 & $\begin{array}{l}\text { A consequência programada era emitida quando o } \\
\text { produto agregado fosse diferente do produto } \\
\text { agregado anterior. A fase se encerrava após o } \\
\text { produto agregado variar conforme o esquema LAG } \\
\text { 3 durante sete partidas consecutivas. }\end{array}$ \\
\hline Extinção & $\begin{array}{l}20 \text { partidas (número fixo) sem que houvesse } \\
\text { consequência para o produto agregado. }\end{array}$ \\
\hline Retorno à Linha de Base & $\begin{array}{l}20 \text { partidas (número fixo), sendo todos os } \\
\text { encontros reforçados. } \\
\text { Ao final da vigésima partida, a mensagem: "Fim!"” } \\
\text { aparecia na tela do computador indicando o fim do } \\
\text { experimento. }\end{array}$ \\
\hline
\end{tabular}




\section{ANÁLISE DOS DADOS}

No trabalho em questão, o pesquisador estava interessado em estabelecer padrões de variação mantidos por consequências em um experimento com metacontingência. A unidade utilizada no estudo foi o encontro de duas peças (produto agregado) em um tabuleiro virtual de 64 células (8x8). Para a análise, foram consideradas a quantidade de partidas jogadas por cada dupla em cada fase dos experimentos, a quantidade de movimentos realizados pelas duplas em cada fase dos experimentos e os valores do índice U, que indicaram a variabilidade da localização do produto agregado em cada fase dos experimentos. Os dados referentes a duração das partidas, fases e experimentos não serão apresentados, considerando que durante o experimento vários participantes fizeram pausas para beberem água e irem ao banheiro.

Esperava-se certa estereotipia na localização dos produtos agregados durante as fases de linha de base e retorno à linha de base, um aumento progressivo da variabilidade da localização dos produtos agregados nas fases com um esquema lag conforme os critérios de variabilidade previamente estabelecidos e um aumento da variabilidade na fase de extinção.

\subsection{RESULTADOS}

As fases "Linha de Base”, "Extinção" e "Retorno à Linha de Base” tiveram um número fixo de partidas. Em função do critério de estabilidade (sete partidas consecutivas em que o critério de variabilidade da fase era atingido), a quantidade mínima de partidas necessárias para que as duplas finalizassem as fases “Lag 1", “Lag 2" e "Lag 3" era, respectivamente, 8, 9 e 10.

A partir do Quadro 2, referente a quantidade de partidas por dupla em cada fase dos experimentos, é possível observar que todas as duplas do experimento, com exceção da dupla 01.4, apresentaram um aumento progressivo no número de partidas. As duplas 01.2, 01.3, 02.1, 
02.2 e 03.2 apresentaram a quantidade mínima de partidas durante a fase "Lag 1", indicando que todas estas duplas atingiram o critério de variabilidade em todas as partidas da fase. A quantidade de partidas na fase "Lag 2" variou consideravelmente para cada dupla, ainda assim as duplas 02.2 e 03.2 apresentaram a quantidade mínima de partidas desta fase. Apenas as duplas 03.1 e 03.2 passaram pela fase "Lag 3" e a diferença da quantidade de partidas para cada dupla foi grande.

Quadro 2 - Quantidade de partidas por dupla em cada fase dos experimentos

\begin{tabular}{|l|c|c|c|c|c|c|}
\hline \multicolumn{7}{|c|}{ Quantidade de Partidas } \\
\hline Dupla & Linha de Base & Lag 1 & Lag 2 & \multicolumn{2}{c|}{ Extinção } \\
\hline 01.1 & 10 & 11 & 48 & \multicolumn{2}{|c|}{20} \\
\hline 01.2 & 10 & 8 & 49 & \multicolumn{2}{|c|}{20} \\
\hline 01.3 & 10 & 8 & 12 & & Ret. à Linha \\
de Base
\end{tabular}

O Quadro 3 apresenta o número de partidas necessárias para que cada dupla atingisse o critério de estabilidade para as fases onde vigorava um esquema lag. As duplas 01.2, 01.3, 02.1, 02.2 e 03.2 cumpriram o critério de variabilidade da fase "Lag 1" desde o início. As duplas 02.2 e 03.2, além de cumprirem com o critério de variabilidade da fase "Lag 1" desde o início da fase, também cumpriram o critério de variabilidade da fase "Lag 2" desde o seu início. 
Quadro 3 - Quantidade de partidas necessárias por dupla até para atingirem o critério de estabilidade de cada fase dos experimentos

\begin{tabular}{|c|c|c|c|}
\hline \multicolumn{4}{|c|}{ Partidas Necessárias para Atingir o Critério de Estabilidade } \\
\hline \multicolumn{4}{|c|}{ Experimento I } \\
\hline Dupla & Lag 1 & & Lag 2 \\
\hline 01.1 & 3 & & 41 \\
\hline 01.2 & 0 & & 42 \\
\hline 01.3 & 0 & & 5 \\
\hline 01.4 & 36 & & 11 \\
\hline \multicolumn{4}{|c|}{ Experimento II } \\
\hline Dupla & Lag 1 & & Lag 2 \\
\hline 02.1 & 0 & & 35 \\
\hline 02.2 & 0 & & 0 \\
\hline \multicolumn{4}{|c|}{ Experimento III } \\
\hline Dupla & Lag 1 & Lag 2 & Lag 3 \\
\hline 03.1 & 9 & 61 & 137 \\
\hline 03.2 & 0 & 0 & 18 \\
\hline
\end{tabular}

Eram necessários no mínimo quatro movimentos por partida para a ocorrência do produto agregado. O Quadro 4 mostra a quantidade de movimentos realizados por cada dupla até o fim das fases dos experimentos. Em virtude do aumento do número fixo de partidas da "Linha de Base", houve um aumento natural de movimentos nos experimentos I e II. A quantidade de movimentos da fase "Lag 1" variou de 47 (dupla 03.2) à 234 (dupla 01.4). Na fase “Lag 2" a quantidade de movimentos variou de 47 (dupla 02.2) à 324 (dupla 03.1). Na fase “Lag 3" a dupla 03.1 realizou 701 movimentos, uma quantidade mais de três vezes superior à da dupla 03.2, que realizou 213. Na fase "Extinção" a quantidade de movimentos variou de 99 (dupla 03.1) à 269 (dupla 01.3). Na fase "Retorno à Linha de Base" a quantidade de movimentos variou de 93 (dupla 03.2) à 121 (02.2). As duplas 01.4 e 02.2 foram as únicas que apresentaram uma quantidade de movimentos na fase "Lag 2" inferior à fase "Lag 1". 
Quadro 4 - Quantidade de movimentos por dupla em cada fase dos experimentos

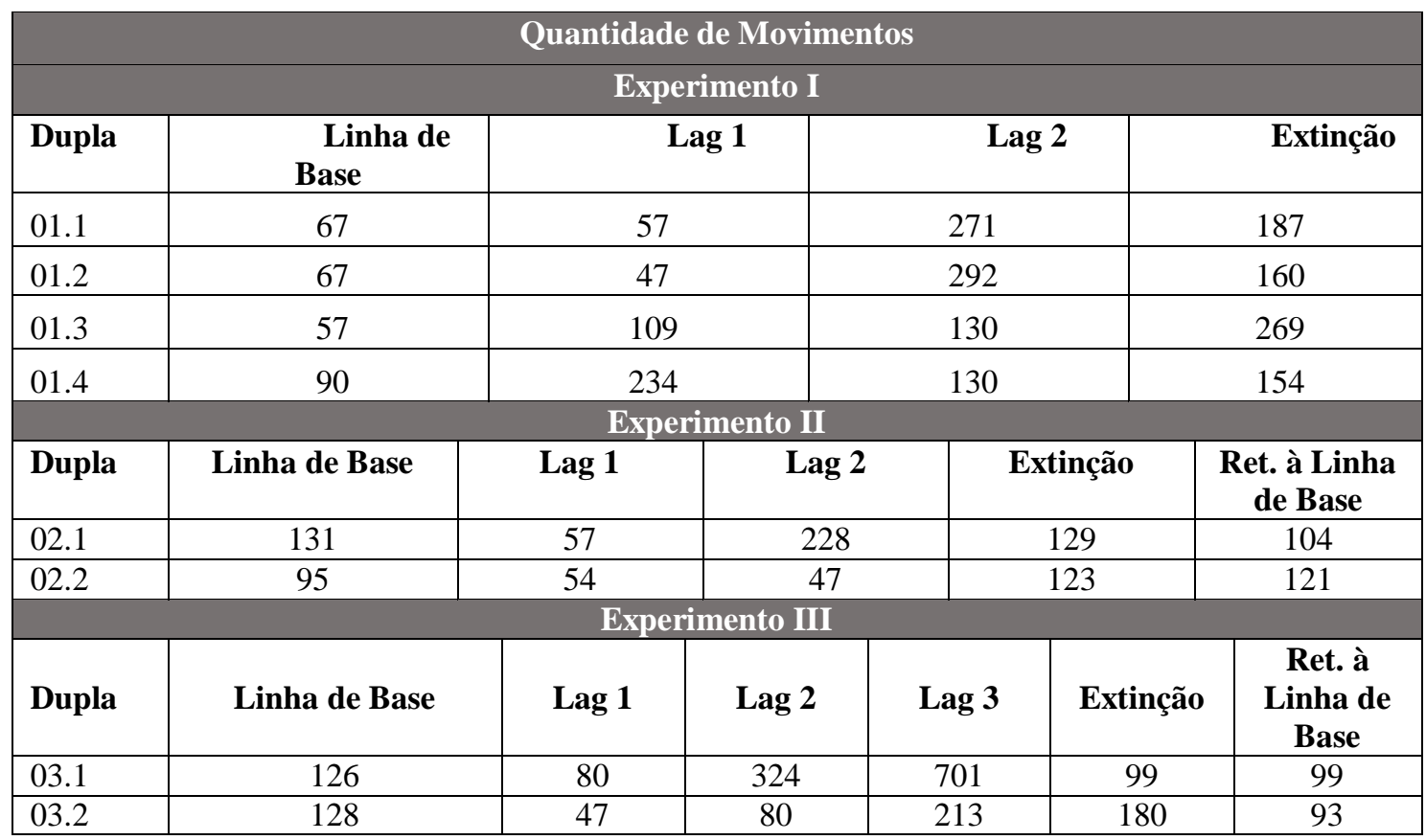

A Figura 5 apresenta a média da quantidade de movimentos por fase em cada experimento. A fase "Lag 3" se destaca em função da grande quantidade de movimentos nesta fase realizados pela dupla 03.2.

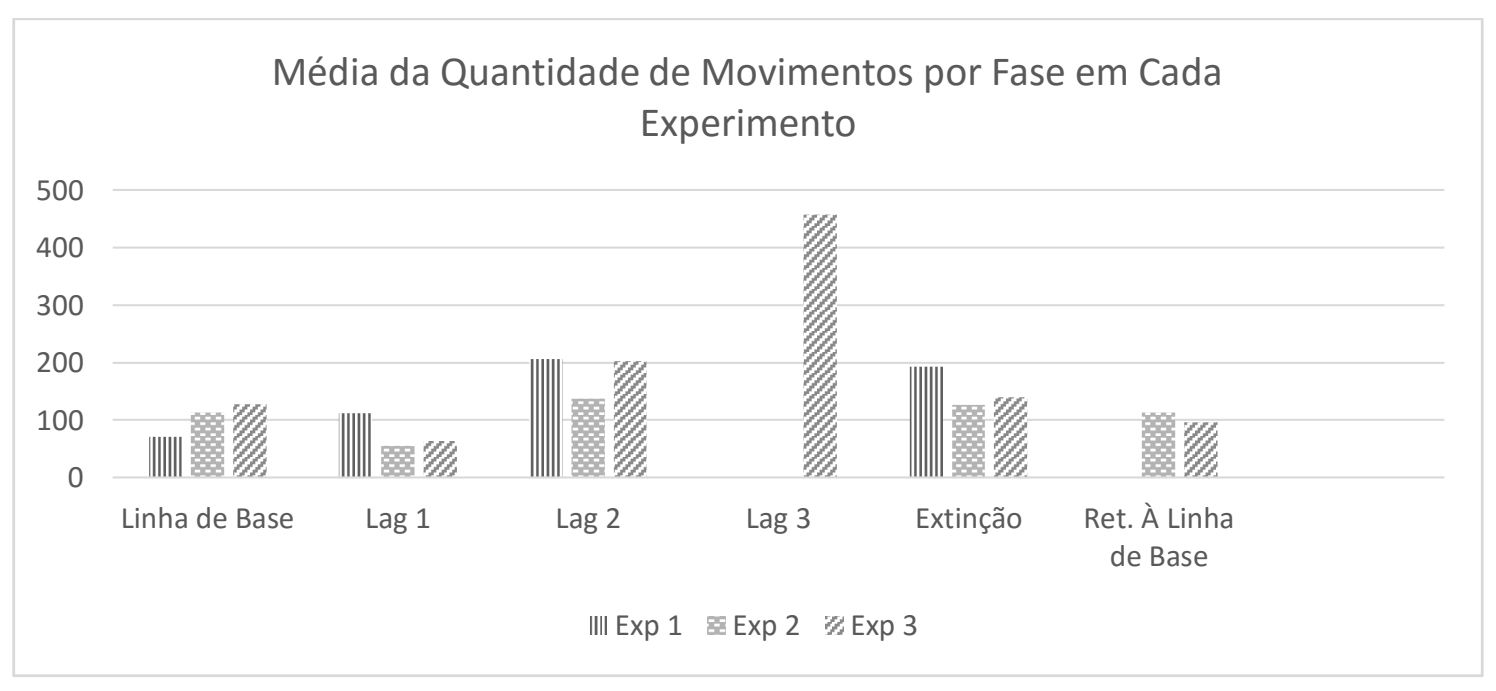

Figura 5 - Média da quantidade de movimentos por fase dos experimentos 
Dentre as possibilidades estatísticas para mensurar a variabilidade do produto agregado, foi utilizado o índice estatístico U em função de seu uso recorrente em trabalhos da área de variabilidade comportamental (Barba \& Hunziker, 2003; Cohen et al., 1990; Hunziker et al., 1996; Hunziker et al., 1998; Morgan \& Neuringer, 1990; Neuringer, 1991; Neuringer, 1992; Neuringer \& Huntley, 1992). O índice U mede a equiprobabilidade de eventos. O comportamento mais variável corresponde, nessa perspectiva, a comportamento menos previsível. Quanto maior o valor de U maior será a variabilidade dos dados em estudo. Nos dados analisados neste trabalho, quanto maior o valor de U (Quadro 5), maior foi a variabilidade na localização do produto agregado durante determinada fase dos experimentos.

No Experimento I, podemos observar um aumento progressivo dos valores do índice U para todas as duplas durante as fases "Linha de Base", "Lag 1" e "Lag 2". Na fase "Extinção" o índice U apontou indicou que houve uma variabilidade considerável com relação à fase "Linha de Base".

No Experimento II os dados se mostram mais irregulares. A dupla 02.1 apresentou um índice U maior na "Linha de Base" com relação à fase "Lag 1". O valor da fase "Lag 2" foi maior que os valores das fases "Linha de Base", "Lag 1" e "Retorno à Linha de Base". Na fase "Extinção" o índice U indicou que houve uma variabilidade maior com relação às outras fases. Os valores do índice $U$ da dupla 02.2 indicam uma maior variabilidade na localização do produto agregado durante a "Linha de Base" com relação às fases "Lag 1" e "Lag 2". A fase “Lag 1" apresentou um índice levemente superior ao da fase "Lag 2". A fase de extinção manteve uma variabilidade maior com relação as outras fases. Durante a fase "Retorno à Linha de Base" houve uma variabilidade menor com relação a fase "Extinção", porém os índices continuaram maiores que nas fases onde havia um esquema lag.

No Experimento III as duas duplas apresentaram um aumento progressivo nos valores do índice U durante as fases "Lag 1" “Lag 2" e "Lag 3". A dupla 03.1 apresentou um valor do 
índice U na fase "Linha de Base", superior aos valores de todas as outras fases pelas quais passaram. O valor do índice U na fase "Retorno à Linha de Base" apresenta uma baixa variabilidade com relação as outras fases da dupla. O valor do índice apresentado na "Linha de Base" pela dupla 03.2 foi superior aos índices das fases "Lag 1" e "Lag 2", idêntico ao da fase "Extinção" e superior ao índice da fase "Retorno à Linha de Base. Na fase "Retorno à Linha de Base" o valor do índice indica uma diminuição na variabilidade com relação as fases "Lag 2", "Lag 3" e "Extinção".

Quadro 5 - Valores do índice estatístico U de cada dupla por fase dos experimentos

\begin{tabular}{|c|c|c|c|c|c|c|}
\hline \multicolumn{7}{|c|}{ Valores do Índice U } \\
\hline \multicolumn{7}{|c|}{ Experimento I } \\
\hline Dupla & Linha de Base & \multicolumn{2}{|c|}{ Lag 1} & \multicolumn{2}{|l|}{ Lag 2} & Extinção \\
\hline 01.1 & 0,301 & \multicolumn{2}{|l|}{0,312} & \multicolumn{2}{|l|}{0,428} & 0,424 \\
\hline 01.2 & 0,133 & \multicolumn{2}{|l|}{0,283} & \multicolumn{2}{|l|}{0,402} & 0,404 \\
\hline 01.3 & 0,301 & \multicolumn{2}{|l|}{0,309} & \multicolumn{2}{|l|}{0,369} & 0,445 \\
\hline 01.4 & 0,223 & \multicolumn{2}{|c|}{0,324} & \multicolumn{2}{|l|}{0,391} & 0,424 \\
\hline \multicolumn{7}{|c|}{ Experimento II } \\
\hline Dupla & Linha de Base & Lag 1 & Lag 2 & \multicolumn{2}{|c|}{ Extinção } & $\begin{array}{c}\text { Ret. à Linha } \\
\text { de Base }\end{array}$ \\
\hline 02.1 & 0,241 & 0,145 & 0,365 & \multicolumn{2}{|c|}{0,414} & 0,293 \\
\hline 02.2 & 0,310 & 0,283 & 0,281 & \multicolumn{2}{|c|}{0,424} & 0,390 \\
\hline \multicolumn{7}{|c|}{ Experimento III } \\
\hline Dupla & Linha de Base & Lag 1 & Lag 2 & Lag 3 & Ext. & $\begin{array}{c}\text { Ret. à } \\
\text { Linha de } \\
\text { Base }\end{array}$ \\
\hline 03.1 & 0,386 & 0,269 & 0,327 & 0,367 & 0,344 & 0,187 \\
\hline 03.2 & 0,410 &, 0283 & 0,326 & 0,442 & 0,410 & 0,299 \\
\hline
\end{tabular}




\section{DISCUSSÃO}

O presente trabalho buscou verificar se é possível produzir padrões variáveis nos produtos agregados de uma metacontingência, mantidos por consequências sociais (mensagem: Parabéns! O objetivo foi alcançado), seguindo o mesmo procedimento dos experimentos realizados por Vasconcelos (2014) e Azevedo (2015). Neste trabalho, foi considerada a variabilidade da localização do produto agregado (encontro das peças) dentro do tabuleiro virtual como a propriedade a ser manipulada. Para a localização do produto agregado fosse considerada diferente, a peça de ao menos um dos dois participantes deveria estar em uma célula diferente do encontro anterior. A consequência programada foi apresentada conforme o critério de variação estabelecido para cada fase onde vigorou uma contingência lag ("Lag 1", "Lag 2" ou “Lag 3").

Sobre a quantidade de partidas realizadas por cada dupla (Quadro 2), nota-se que, com exceção de uma, todas apresentaram um aumento progressivo durante as fases em que havia um esquema lag. Somente a dupla 01.4 reduziu a quantidade de partidas na fase "Lag 2". Esperava-se que em função da complexidade de cada fase, houvesse um aumento progressivo. Vale salientar que a quantidade de partidas realizadas pela dupla 01.4 durante a fase "Lag 1" foi a mais alta dos experimentos. A quantidade de partidas da dupla em questão caiu pela metade na fase "Lag 2", o que poderia estar relacionado com o controle do comportamento dos participantes pela contingência lag 2.

Ressalta-se que cinco duplas cumpriram o critério de estabilidade da fase "Lag 1" desde o seu início. O mesmo ocorreu com duas duplas durante a fase "Lag 2". Considerando a quantidade de possibilidade de encontros possíveis no tabuleiro, os esquemas planejados para estas fases poderiam ser pouco exigentes. A dupla 03.2, que atingiu o critério de estabilidade desde o início das fases "Lag 1" e "Lag 2", precisou de 18 partidas para atingir o critério de 
estabilidade da fase "Lag 3". Estes dados indicam que em experimentos futuros os participantes poderiam começar o experimento com um mais alto valor para o " $n$ ", dos esquemas lag. $\mathrm{O}$ desempenho da dupla também pode estar relacionado a repertórios específicos dos participantes, o que poderia ser trabalhado definindo a amostra de participantes a partir de aspectos como a área de conhecimento em que seu curso universitário se situa.

Apesar de a quantidade dos movimentos realizados pelas duplas em cada fase ter sido assistemática, podemos observar algumas regularidades nas médias da quantidade de movimentos por fase de cada experimento. A média da quantidade de movimentos aumentou progressivamente durante as fases em que um esquema lag vigorou. Houve um aumento na média da quantidade de movimentos realizados na fase "Extinção" com relação à fase "Linha de Base". Nos Experimentos II e III, onde havia a fase "Retorno à Linha de Base", foi possível observar uma queda na média da quantidade de movimentos realizados pelas duplas com relação à fase "Lag 2" no Experimento II, e às fases "Lag 2" e "Lag 3" no Experimento III. Os dados, indicam que há uma relação entre o aumento dos critérios de variabilidade para cada fase e o aumento do número médio de movimentos realizados em cada experimento.

Os dados referentes à quantidade de partidas e à média de movimentos na fase "Linha de Base" dos experimentos I, II e III, e da fase "Retorno à Linha de Base", dos experimentos II e III, quando comparados com a fase "Extinção", podem ser equiparados aos dados produzidos na literatura sobre extinção em contingências individuais (Millenson, 1975), na medida em que houve alteração na taxa de produtos agregados produzidas a partir do entrelaçamento do comportamento dos participantes. Além disso, Millenson (1975) destava que a sequência de respostas estabelecida a partir do reforçamento de comportamentos individuais se degenera na extinção, o que poderia explicar uma quantidade maior na média de movimentos na fase "Extinção" dos experimentos. 
Como há uma diminuição no número de reforços em cada fase, esta poderia também ser uma variável responsável pelo aumento na variabilidade entre os esquemas lag de diferentes valores (Neuringer, 1985). Como a variabilidade diminui quando as contingências de variação são suspensas, temos indícios de que a contingência lag n tem um papel nos níveis de variação obtidos, mesmo que o total de reforços no Retorno à Linha de Base não tenha sido acoplado à fase anterior.

Os valores do índice U encontrados mostram que, com exceção da dupla 02.2, houve um aumento progressivo na variabilidade da localização dos produtos agregados em todas as duplas que participaram dos experimentos. Os valores referentes às fases "Lag 1" e "Lag 2" da dupla 02.2 estão bem próximos e vale ressaltar que esta dupla atingiu o critério de estabilidade das fases com um esquema lag desde o início. Os valores de U também foram altos na fase "Extinção" dos experimentos, o que corrobora com a literatura sobre variabilidade induzida por contingências (Antonitis, 1951).

Os experimentos mostraram que é possível aumentar a variabilidade de propriedades do produto agregado de uma metacontingência consequenciando diferentes padrões de variabilidade e, assim como nos trabalhos de Azevedo (2015) e Vasconcelos (2014), os dados apontam que a manipulação de metacontingências estão sujeitas a parâmetros e procedimentos utilizados de forma equivalente para o estudo de contingências individuais.

Com relação aos estudos anteriores (Dos Santos, 2011; Kracker, 2013), os experimentos realizados conseguiram alcançar níveis de variabilidade maior no produto agregado (lag 2 e lag 3), com a vantagem de ter um procedimento mais simples, mais barato e mais rápido, possibilitando um maior número de replicações e um bom controle experimental.

Apesar dos desafios no estudo de duas áreas tão complexas - a seleção de práticas culturais e a variabilidade operante -, a utilização de um procedimento simples, que permite a produção de produtos agregados sem envolver consequências diferenciais para cada indivíduo, 
se mostra promissora. Durante o desenvolvimento dos experimentos, não houve desistência de participantes e as duplas conseguiram desenvolver a atividade proposta sem maiores problemas. O procedimento utilizado permite, com alguns ajustes na configuração, o controle de diferentes propriedades do produto agregado, e a programação de diferentes esquemas de seleção cultural, e ainda oferece ao pesquisador um output claro dos dados registrados.

Para experimentos futuros com variabilidade operante de produtos agregados vale a pena considerar alguns aspectos.

Os dados sobre a duração das fases e das partidas podem ser uma ferramenta interessante para o estudo da variabilidade de propriedades do produto agregado. Para isso, o pesquisador deve considerar a limitação de pausas dos participantes durante o experimento, o que não implicaria em danos aos participantes, haja vista que as sessões experimentais duraram em média uma hora e trinta minutos.

Aumentar o número de partidas nas fases de "Linha de Base", "Retorno à Linha de Base" e Extinção poderia fornecer dados mais claros sobre a estereotipia e a variabilidade induzidas pelos esquemas vigentes. Também seria interessante diversificar mais a amostra de participantes, ou fazer comparações entre amostras distintas, como estudantes de cursos vinculados às ciências humanas e estudantes de cursos vinculados às ciências exatas.

O registro das conversas entre os membros da dupla pode ajudar a verificar a influência da formulação de regras no desempenho durante o experimento. Outro registro poderia ser feito pedindo para que os participantes descrevessem a estratégia utilizada para passar de uma fase para outra.

Por haver pouco material publicado sobre variabilidade de práticas culturais, buscou-se usar como medida de variabilidade da localização dos produtos agregados os valores do índice U. Convém analisar, com o suporte de profissionais estatísticos, outras possibilidades de testes 
e modelos que possam fornecer novas análises para o estudo da variabilidade de práticas culturais.

Em função do tempo destinado à conclusão deste trabalho e algumas dificuldades inerentes a criação de um programa adequado ao procedimento proposto, não foi possível realizar um número maior de replicações do experimento III, o que poderia ser feito em trabalhos posteriores.

Considerando que os estudos experimentais com o terceiro nível de seleção do comportamento humano são recentes e ainda possuem uma série de desafios conceituais e empíricos, o trabalho realizado contribui para que tenhamos uma base empírica mais sólida e possamos intervir de forma adequada a fim de solucionar problemas sociais e garantir uma melhor qualidade de vida aos nossos pares. 


\section{REFERÊNCIAS}

Abreu-Rodrigues, J. (2005). Variabilidade Comportamental. In J. Abreu-Rodrigues \& M. R. Ribeiro (Orgs.), Análise do comportamento: pesquisa, teoria e aplicação (pp. 81-98). Porto Alegre: Artmed.

Amorim, V.C. (2010). Análogos experimentais de metacontingências: efeitos da intermitência da consequência cultural (Dissertação de mestrado). Pontifícia Universidade Católica de São Paulo, São Paulo.

Andery, M. A. P. A., Micheletto, N., \& Sério, T. M. A. P. (2005). A análise de fenômenos sociais: esboçando uma proposta para a identificação de contingências entrelaçadas e metacontingências. In J. C. Todorov, R. C. Martone, \& M. B. Moreira (Orgs.). Metacontingências: comportamento, cultura e sociedade. Santo André: ESETec.

Andery, M. A., \& Sério, T. M. (1999). O conceito de metacontingência: afinal, a velha contingência de reforçamento é suficiente? In R. A. Banaco (Org.). Sobre comportamento e cognição: aspectos teóricos, metodológicos e de formação em análise do comportamento e terapia cognitivista (2a ed., pp. 106-116). Santo André: ESEtec.

Antonitis, J. J. (1951). Response variability in rat during conditioning extinction, and reconditioning. Journal of Experimental Psychology, 42(4), 273-281.

Attneave, F. (1959). Applications of information theory to psychology: a summary of basic concepts, methods and results. New York: Holt-Dryden Book: Henry Holt.

Azevedo, R. M. F. (2015). Controle discriminativo em metacontingência (Dissertação de mestrado). Universidade de Brasília, Brasília.

Baia, F. H. (2008). Microssociedades no laboratório: o efeito de consequências culturais externas sobre culturantes (Dissertação de mestrado). Universidade de Brasília, Brasília.

Barba, L. S. (2010). Variabilidade comportamental operante e o esquema de reforçamento LagN. Acta Comportamentalia, 18(2), 155-188.

Barba, L. S., \& Hunziker, M. H. L. (2003). Variabilidade comportamental produzida por dois esquemas de reforçamento. Acta Comportamentalia, 10(1), 5-22.

Brocal, A. L. (2010). Análogos experimentais de metacontingências: os efeitos da retirada da consequência individual (Dissertação de mestrado). Pontifícia Universidade Católica de São Paulo, São Paulo.

Bullerjhann, P. B. (2009). Análogos experimentais de fenômenos sociais: os efeitos das conseqüências culturais (Dissertação de mestrado). Pontifícia Universidade Católica de São Paulo, São Paulo.

Cabral, M. D. C. (2014). Metacontingências envolvidas no processo legislativo da Lei 12.433, de 29 de junho de 2011 (Dissertação de mestrado). Universidade de Brasília, Brasília. 
Caldas, R. A. (2009). Análogos experimentais de seleção e extinção de metacontingências (Dissertação de mestrado). Pontifícia Universidade Católica de São Paulo, São Paulo.

Carvalho, I. C. V. (2013). Contingências e metacontingências na lei de diretrizes e bases da educação nacional - LDB (Dissertação de mestrado). Universidade de Brasília, Brasília.

Catania, A. C. (1996). On the origins of behavior structure. In T. R. Zentall, \& P. M. Smeets (Orgs.), Stimulus class formation in humans and animals (pp. 3-12). New York: Elsevier.

Cohen, L., Neuringer, A., \& Rhodes, D. (1990). Effects of ethanol on reinforced variations and repetitions by rats under a multiple schedule. Journal of the Experimental Analysis of Behavior, 54(1), 1-12.

Costa, D. C. (2009). Dilema do Prisioneiro: Efeito das consequências individuais e culturais (Dissertação de mestrado). Universidade de Brasília, Brasília.

Costa, D. C., Nogueira, C. P. V., \& Vasconcelos, L. A. (2012). Effects of communication and cultural consequences on choices combinations in INPDG with four participants. Revista Latinoamericana de Psícologia, 44(1), 121-131.

Cruvinel, A. C., \& Sério, T. M. A. P. (2008). Variabilidade Comportamental: a Produção de Variabilidade da Duração da Resposta. Acta Comportamentalia, 16(1), 5-23.

Darwin, C. (2004). A origem das espécies (J. Green, Trad.). São Paulo: Martin Claret. (Trabalho original publicado em 1859).

Denney, J., \& Neuringer, A. (1998). Behavioral variability is controlled by discriminative stimuli. Animal Learning \& Behavior, 26(2), 154-162.

Bizo, L \& Doolan, K. (2013). Reinforced behavioral variability in humans. The Psychological Record, 63(4), 725-734.

Dos Santos, P. M. (2011). É possível produzir variabilidade em metacontingência?. (Dissertação de mestrado). Pontifícia Universidade Católica de São Paulo, São Paulo.

Eckerman, D., \& Lanson, R. (1969). Variability of response location for pigeons responding under continuous reinforcement, intermittent reinforcement, and extinction. Journal of Experimental Analysis of Behavior, 12(1), 73-80.

Ferster, C. B., \& Skinner, B.F. (1957). Schedules of reinforcement. New York: AppletonCentury-Crofts.

Gadelha, C. T. (2010). Evolução cultural em análogos experimentais de metacontingências: seleção de diferentes produtos agregados (Dissertação de mestrado). Pontifícia Universidade Católica de São Paulo, São Paulo.

Glenn, S. S. (1986). Metacontingencies in Walden Two. Behavior Analysis and Social Action, $5(1-2), 2-8$. 
Glenn, S. S. (1988). Contingencies e metacontingencies: toward a synthesis of behavior analysis na cultural materialism. The Behavior Analyst, 11(2), 161-179.

Glenn, S., \& Malott, M. (2004). Complexity and selection: Implications for organizational change. Behavior and Social Issues, 13, 89-106.

Houmanfar, R., \& Rodrigues, N. J. (2006). The metacontingency and the behavior contingency: Points of contact and departure. Behavior and Social Issues, 15(1), 13-30.

Hull, D. L., Langman, R. E., \& Glenn, S. S. (2001). A general account of selection: Biology, immunology, and behavior. Behavioral and Brain Sciences, 24(3), 511-573.

Hunziker, M. H. L., \& Moreno, R. (2000). Análise da noção de variabilidade comportamental. Psicologia: Teoria e Pesquisa, 16(2), 135-143.

Hunziker, M. H. L., Caramori, F. C., Silva, A. P., \& Barba, L. S. (1998). Efeitos da história de reforçamento sobre a variabilidade comportamental. Psicologia: Teoria e Pesquisa, 14, 149-159.

Hunziker, M. H. L., Saldana, L., \& Neuringer, A. (1996). Behavioral variability in SHR and WKY rats as a function of rearing environment and reinforcement contingency. Journal of the Experimental Analysis of Behavior, 65(1), 129-144.

Kracker, C. K. (2013). Variabilidade comportamental e seleção cultural: efeitos de esquemas análogos a reforçamento diferencial de variabilidade LAG e a CRF em processos de seleção de metacontingências (Dissertação de mestrado). Pontifícia Universidade Católica de São Paulo, São Paulo.

Lachter, G. D., \& Corey, J. R. (1982). Variability of the duration of an operant. Behavior Analysis Letters, 2, 97-102.

Lamal, P. A. (1991). Three metacontingencies in the Pre-Perestroika Soviet Union. Behavior and Social Issues, 1, 75-90.

Lamal, P. A., \& Greenspoon, J. (1992). Congressional metacontingencies. Behavior and Social Issues, 2, 71-81.

Lattal, K. A. (1995). Contingency and behavior analysis. The Behavior Analyst, 18(2), 204224.

Malott, M., \& Glenn, S. S. (2006). Targets of intervention in cultural and behavioral change. Behavior and Social Issues, 15, 31-56.

Martins, A. L. A. (2009). O Sistema Único de Saúde: Contingências e metacontingências nas Leis Orgânicas de Saúde (Dissertação de mestrado), Universidade de Brasília, Brasília.

Martone, R. C. (2008). Efeitos de consequências externas e de mudanças na constituição do grupo sobre a distribuição dos ganhos em uma metacontingência experimental (Tese de Doutorado). Universidade de Brasília, Brasília. 
Martone, R. C., \& Todorov, J. C. (2007). O desenvolvimento do conceito de metacontingência. Revista Brasileira de Análise do Comportamento, 3(2), 181-190.

Mechner, F. (2011). Why behavior analysis needs a formal symbolic language for codifying behavioral contingencies. European Journal of Behavior Analysis, 12, 93-104.

Melo, C. M. (2004). A concepção de homem no Behaviorismo Radical de Skinner: Um compromisso com o 'bem' da cultura (Dissertação de mestrado). Universidade Federal de São Carlos, São Paulo.

Melo, C. M., \& De Rose, J. C. C. (2012). A sobrevivência das culturas em Skinner: um diálogo com o materialismo cultural de Harris. Psicologia: Teoria e Pesquisa, 28(1), 119-128.

Micheletto, N. (1999). Variação e seleção: As novas possibilidades de compreensão do comportamento. In R. A. Banaco, Sobre comportamento e cognição (pp. 1117-1131). Santo André: Arbytes.

Millenson, J. R. (1975). Princípios de análise do comportamento. Brasília, DF: Coordenada.

Morgan, L., \& Neuringer, A. (1990). Behavioral variability as a function of response topography and reinforcement contingency. Animal Learning and Behavior, 18(3), 257263.

Naves, A. R. C. X., \& Vasconcelos, L. A. (2008). O estudo da família: Contingências e metacontingências. Revista Brasileira de Análise do Comportamento, 4(1), 13-25.

Neuringer, A. (1991). Operant variability and repetition as functions of interresponse time. Journal of experimental Psychology: Animal Behavior Processes, 17(1), 3-12.

Neuringer, A. (1992). Choosing to vary and repeat. Psychological Science, 3(4), 246-250.

Neuringer, A. (2002). Operant variability: Evidence, functions, and theory. Psychonomic Bulletin \& Review, 9(4), 672-705.

Neuringer, A. (2004). Reinforced variability in animals and people. American Psychologist, 59(9), 891-906.

Neuringer, A., \& Huntley, R. W. (1992). Reinforced variability in rats: Effects of gender, age and contingency. Physiology \& Behavior, 51(1), 145-149.

Neves, A. B. V. S., Woelz, T. A. R., \& Glenn, S. S. (2012). Effect of resource scarcity on dyadic fitness in a simulation of two-hunter nomoclones. Revista Latinoamericana de Psicología, 44(1), 159-167.

Nogueira, C. P. V. (2009). Seleção de diferentes culturantes no Dilema do Prisioneiro: Efeito da interação entre a consequência cultural, escolhas simultâneas ou sequenciais e a comunicação (Dissertação de mestrado). Universidade de Brasília, Brasília.

Oda, L. V. (2009). Investigação das interações verbais em um análogo experimental de metacontingência (Dissertação de mestrado) Pontifícia Universidade Católica de São Paulo, São Paulo. 
Ortu, D., Becker, A. M., Woelz, T. A. R., \& Glenn, S. S. (2012). An iterated four-player prisoner's dilemma game with an external selecting agent: A Metacontingency Experiment. Revista Latinoamericana de Psicología, 44(1), 111-120.

Page, S., \& Neuringer, A. (1985). Variability is an operant. Journal of Experimental Psychology: Animal Behavior Process, 11(3), 429-452.

Pereira, J. M. C. (2008). Investigação experimental de metacontingências: Separação do produto agregado e da consequência individual (Dissertação de mestrado). Pontifícia Universidade Católica de São Paulo, São Paulo.

Prudêncio, M. R. A. (2006). Leis e metacontingências: Análise do controle do estatuto da criança e do adolescente sobre práticas jurídicas em processos de infração de adolescentes no Distrito Federal (Dissertação de mestrado). Universidade de Brasília, Brasília.

Rakos, R. (1991). Perestroika, Glasnost, and international cooperation: A behavior analysis. Behavior and Social Issues, 1, 91-100.

Schick, K. (1971). Operants. Journal of the Experimental Analysis of Behavior, 15(3), 413-423.

Schoenfeld, W. N., Harris, A. H., \& Farmer, J. (1966). Conditioning response variability. Psychological Reports, 19, 551-557.

Schwartz, B. (1980). Development of complex stereotyped behavior in pigeons. Journal of the Experimental Analysis of Behavior, 33(2), 153-166.

Schwartz, B. (1982). Failure to produce response variability with reinforcement. Journal of the Experimental Analysis of Behavior, 37(2), 171-181.

Sénéchal-Machado, V. L., \& Todorov, J. C. (2008). A travessia na faixa de pedestre em Brasília (DF/Brasil): Exemplo de uma intervenção cultural. Revista Brasileira de Análise do Comportamento, 4(2), 191-204.

Sidman, M. (1960). Tactics of scientific research. New York: Basic Books

Skinner, B. F. (1966). The behavior of organisms: An experimental analysis. New York: Appleton-Century. (Trabalho original publicado em 1938).

Skinner, B. F. (1980). Contingências do reforço: Uma análise teórica (R. Moreno, trad., Coleção Os Pensadores). São Paulo: Abril Cultural. (Trabalho original publicado em 1969).

Skinner, B. F. (1981). Selection by consequences. Science, 213(4507), 501-514.

Skinner, B. F. (2003). Ciência e comportamento humano (11a ed.). São Paulo: Martins Fontes. (Obra original publicada em 1953).

Stokes, P. D., \& Balsam, P. (2001). An optimal period for setting sustained variability levels. Psychonomic Bulletin \& Review, 8(1), 177-184. 
Todorov, J. C. (1987). A Constituição como metacontingência. Psicologia: Ciência e Profissão, $7(1), 9-13$.

Todorov, J. C. (2002). A evolução do conceito de operante. Psicologia: Teoria e Pesquisa, $18(2), 123-127$.

Todorov, J. C. (2006). The metacontingency as aconceptual tool. Behavior and Social Issues, $15,92-94$.

Todorov, J. C. (2007). A psicologia como o estudo de interações. Psicologia: Teoria e Pesquisa, 5, 347-356. Reimpressão em Psicologia: Teoria e Pesquisa, 23, 57-61. (Artigo original publicado em 1989).

Todorov, J. C. (2009). Behavioral analysis of non-experimental data associated with cultural practices. Behavior and Social Issues, 18, 10-14.

Todorov, J. C. (2010). Schedules of cultural selection: Comments on "Emergence and Metacontingency". Behavior and Social Issues, 19, 86-89.

Todorov, J. C. (2012a). Contingências de seleção cultural. Revista Brasileira de Análise do Comportamento, 8(2), 49-59.

Todorov, J. C. (2012b). Metacontingências e a análise comportamental de práticas culturais. Clínica \& Cultura, 1(1), 36-45.

Todorov, J. C. (2012c). Sobre uma definição de comportamento. Perspectivas em Análise do Comportamento, 3(1), 32-37.

Todorov, J. C. (2013). Conservation and transformation of cultural practices through contingencies and metacontingencies. Behavior and Social Issues, 22, 64-73.

Todorov, J. C., \& Vianney, J. B. (2013). Xadrez (Versão 7.3) [Programa de computador]. Brasília, DF: Brasil.

Vasconcelos, I. G. (2014) Um procedimento experimental de modelagem de respostas para seleção do produto agregado em metacontingências (Dissertação de mestrado). Universidade de Brasília, Brasília.

Vichi, C. (2004). Igualdade ou desigualdade em pequeno grupo: Um análogo experimental de manipulação de uma prática cultural (Dissertação de mestrado). Pontifícia Universidade Católica de São Paulo, São Paulo.

Vichi, C., Andery, M. A. P. A., \& Glenn, S. S. (2009). A metacontingency experiment: The effects of contingent consequences on patterns of interlocking contingencies of reinforcement. Behavior and Social Issues, 18, 41-57.

Vieira, M.C. (2010). Condições antecedentes participam de metacontingências?. (Dissertação de mestrado). Pontifícia Universidade Católica de São Paulo, São Paulo. 
ANEXOS 
Anexo A - Termo de consentimento livre e esclarecido

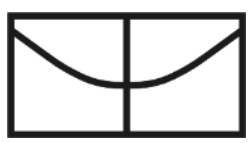

UNIVERSIDADE DE BRASÍLIA

DEPART. DE PROCESSOS PSICOLÓGICOS BÁSICOS - INSTITUTO DE

PSICOLOGIA

\section{TERMO DE CONSENTIMENTO LIVRE E ESCLARECIDO}

Convidamos o(a) Sr(a) para participar da Pesquisa "Variabilidade do produto agregado" sob a responsabilidade do pesquisador Rodrigo Marquez Martins de Oliveira e sob orientação do Prof. João Cláudio Todorov, a qual pretende investigar comportamentos em situações de interação social.

Sua participação é voluntária e se dará por meio da participação em um jogo de computador a ser realizado em dupla.

Mesmo após o início da atividade, você poderá desistir a qualquer momento. Você também tem o direito e a liberdade de retirar seu consentimento em qualquer fase da pesquisa, seja antes ou depois da coleta dos dados, independente do motivo e sem nenhum prejuízo a sua pessoa. O caráter da sua participação é voluntário.

Os resultados da pesquisa serão analisados e publicados, mas sua identidade não será divulgada, sendo guardada em sigilo. Para qualquer outra informação, o(a) Sr(a) poderá entrar em contato com o pesquisador no endereço UNB-ICC Sul - Instituto de Psicologia Laboratório AEC - Subsolo, ou pelo email: rodrigommoliveira@ hotmail.com.

Este projeto foi submetido à Plataforma Brasil para análise dos aspectos éticos envolvidos. 


\section{Consentimento Pós-Informação}

$\mathrm{Eu}$, fui informado sobre o que o pesquisador quer fazer e porque precisa da minha colaboração, e entendi a explicação. Por isso, concordo em participar do projeto, sabendo que não vou ganhar nada e que posso sair quando quiser. Este documento é emitido em duas vias que serão ambas assinadas por mim e pelo pesquisador, ficando uma via com cada um de nós.

Data:

Assinatura do participante

Assinatura do Pesquisador Responsável 


\section{Anexo B - Ficha de Identificação}

Ficha de Identificação

(Estas informações serão de uso restrito dos pesquisadores e não serão divulgadas)

Nome:

Idade:

E-mail:

Telefone:

Curso:

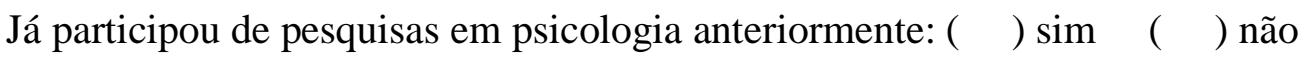

Gostaria de receber informações posteriores sobre a pesquisa: $(\quad) \operatorname{sim} \quad(\quad)$ não 